\title{
Laboratory study of frazil ice accumulation under wave conditions
}

\author{
S. De la Rosa ${ }^{1,2}$ and S. Maus ${ }^{1}$ \\ ${ }^{1}$ Geophysical Institute, University of Bergen, Allégaten 70, 5007, Bergen, Norway \\ ${ }^{2}$ Nansen Environmental and Remote Sensing Center/Mohn-Sverdrup Center, Thormøhlensgate 47, 5006, Bergen, Norway
}

Correspondence to: S. De la Rosa (sara.delarosa@nersc.no)

Received: 27 May 2011 - Published in The Cryosphere Discuss.: 8 July 2011

Revised: 13 January 2012 - Accepted: 24 January 2012 - Published: 9 February 2012

\begin{abstract}
Ice growth in turbulent seawater is often accompanied by the accumulation of frazil ice crystals at its surface, forming a grease ice layer. The thickness and volume fraction of this ice layer play an important role in shaping the gradual transition from a loose to a solid ice cover, however, observations are very sparse. Here we analyse an extensive set of observations of frazil ice, grown in two parallel tanks with controlled wave conditions and thermal forcing, focusing on the first one to two days of grease ice accumulation. The following unresolved issues are addressed: (i) at which volume fraction the frazil crystals' rising process starts and how densely they accumulate at the surface, (ii) how the grease ice solid fraction and salinity evolve with time until solid ice starts to form and (iii) how do these conditions affect, and are affected by, waves and heat loss from the ice. We obtained estimates of the minimum initial grease ice solid fraction (0.03-0.05) and the maximum solid fraction to which it accumulates before freezing into pancakes (0.23-0.31). The equivalent thickness of solid ice that needs to be accumulated until grease ice packs close to maximum (95\% of the compaction accomplished), was estimated as 0.4 to $1.2 \mathrm{~cm}$. Comparison of grease ice thickness and wave observations indicates that a grease ice layer first begins to affect the wave field significantly when its thickness exceeds the initial wave amplitude. These results are relevant for modelling frazil ice accumulation and freeze-up of leads, polynyas and along the seasonal ice zone.
\end{abstract}

\section{Introduction}

The growth of ice in open turbulent seawater is a regular process within a dynamic ice cover that undergoes frequent opening and closing, such as leads and polynyas. Under most conditions it starts by the nucleation of small crystals, called frazil ice. When wave- and current-generated turbulence is no longer capable of keeping the frazil ice in suspen- sion within the water column, the crystals rise to the surface and accumulate in a layer of higher ice volume fraction. $\mathrm{Ag}$ glomeration increases crystal interaction, which in turn implies an increased near-surface viscosity and damping of the oceanic turbulence. This positive feedback preconditions the freeze-up of the granular surface ice skim, often beginning in pancake-like patches of frazil ice referred to as shuga, then evolving to solid pancakes. This type of ice formation occurs on short time scales in highly dynamic turbulent ocean conditions and is very difficult to monitor. Even its basic properties such as thickness, salinity and solid fraction are still not well understood. However, the formation of such wave-induced frazil-pancake ice may become more recurrent in Arctic regions, including the open water seasonal ice zone (Kinnard et al., 2008).

Wadhams and Wilkinson (1999) presented one of the few extensive ice sampling studies of the frazil/grease and pancake cover formed in the Odden ice tongue of the Greenland Sea, a region in the northern Polar Region known for extensive new ice formation in the presence of waves. Laboratory experiments provide a more accessible and controlled environment to study this type of young ice growth. However, only a few studies so far considered frazil ice formation in a wave field and even fewer studies have taken place in water tank dimensions larger than a few meters. We highlight the studies of sea ice growing under turbulent conditions carried out by Martin and Kauffman (1981), Wadhams et al. (1988) and Newyear and Martin (1997), discussing simple models of wave damping in grease ice. These studies indicate that the accumulation thickness of frazil ice crystals is limited by the energy flux from waves. However, a number of uncertainties remain regarding, for example, how the volume fraction, salinity and thickness of the grease ice evolve until the onset of pancake formation, and how these properties are related to observed wave conditions. Wilkinson et al. (2009) briefly introduced a multidisciplinary study of laboratory grown frazil and pancake ice under turbulent conditions with a unique 
spatial and temporal resolution, compared to previous laboratory studies. The goals of the present paper are to give an overview of these latter experiments: present the extensive observations, describe the stage and evolution of a frazil ice field and to advance the understanding of frazil ice accumulation under wave conditions. The key uncertainties that we address include: (i) at which volume fraction the crystal rising process starts and how densely they accumulate at the surface, (ii) how this solid fraction and the corresponding bulk salinity of the grease ice evolves with time until solid ice starts to form, and (iii) how do these conditions affect and are affected by - waves and heat loss from the ice. The outline of this paper is as follows: Sect. 2 describes the experiment set-up and measurements made. Section 3 presents the observed spatial and temporal evolution of the measured properties: ice thickness, and salinity. Section 4 describes the derived properties, solid volume fraction and equivalent ice thickness. In Sect. 5, the temporal evolution is analysed and discussed with respect to overall ice growth driven by thermal forcing, and to the imposed wave field and its attenuation. We further analyse how the solid fraction and thickness change due to the transition from grease ice to solid pancakes and the mechanical redistribution by waves of known amplitude. Section 6 summarizes our main conclusions.

\section{Experiment setup}

Four ice-growth experiments carried out in two identically sized tanks under different wave scenarios are presented here. These are part of the Reduced Ice Cover in the Arctic Ocean (RECARO) project that took place in two phases, during late 2007 and early 2008 at the Hamburg Ship Model Basin (Wilkinson et al., 2009). A schematic layout of each tank and instrument set-up is given in Fig. 1. The tank at the left of the schema was a quiescent tank, which remained undisturbed from wave motion. The two tanks to the right of Fig. 1 were the wave-induced tanks in which the ice measurements presented here were made. A wave paddle at one end of each tank kept the water well mixed so that ice would form under turbulent wave conditions. Sealed wooden barriers separated the three tanks from each other and each was filled with a $\mathrm{NaCl}$ solution. The laboratory room temperature was maintained below freezing with cooling plates installed along the laboratory roof. Each of the four experiments consisted of two parallel runs with very similar conditions. Table 1 lists the basic physical conditions and ice growth characteristics for each experiment. Table 2 lists the wave properties (i.e. range of wavelengths) applied in each case. E1 to $\mathrm{E} 4$ are the names given to each experiment; A and B are the names given to each tank (as labelled in Fig. 1). The same experiment/tank definition is used throughout this paper.

We aimed to start all experiments with completely ice-free conditions, but measurements for E2 and E4, the follow-up experiments for E1 and E3 respectively, could only be started
5-10 $\mathrm{h}$ after the initiation of ice formation (due to inaccessibility to the laboratory facility over night). All experiments nonetheless, included the full period of freezing from open water conditions until the formation of pancake ice and up to $30 \mathrm{~h}$ of frazil measurements are available for each. For E1 and E3 the water depth $\left(H_{\mathrm{w}}\right)$ was $0.85 \mathrm{~m}$, for E2 it was $0.70 \mathrm{~m}$ and for $\mathrm{E} 40.76 \mathrm{~m}$. The experiment of longest duration and most regular sampling was E1 (see Table 1).

A few pertinent results from these experiments have already been published. Wang and Shen (2010a) presented results for the end of E3 (not shown here), focusing on the wave attenuation and viscosity relation (tanks 2 and 3 in their paper, corresponds to tanks A and B here, respectively). De la Rosa et al. (2011) presented results from the latter half of $\mathrm{E} 2$, tank A, using infrared surface temperature data to focus on the thermodynamic and surface area cover changes during transition from a well-established frazil layer to pancake ice. (Note, hour 19 from E2 presented here corresponds to the start time 0 in the latter paper). Observations presented and analysed in this paper are primarily from loose, nonsolidified frazil ice and to a lesser extent, shuga and pancake measurements.

\subsection{Air and water temperature and water salinity}

Two temperature chains of platinum resistance thermometer (Pico Pt-100) sensors were set up in the quiescent tank and covered air temperatures up to $+16 \mathrm{~cm}$ above the surface. The temperature sensors were separated by $2 \mathrm{~cm}$. During E3 and E4 the two temperature chains were located on the opposite end of the quiescent tank (crossed squares in Fig. 1), and air temperature was recorded at $+8 \mathrm{~cm}$ above the surface. Water electrolytic conductivity and temperature were continuously measured during experiments E1 and E2, with two Conductivity-Temperature-Depth (CTD) recorders (MicroCat SBE37-SM) placed at fixed locations within the centre of each tank, at 0.20 and $0.45 \mathrm{~m}$ from the tank floor (hereafter referred to as bottom and top CTD's, respectively). No CTD measurements are available for E3. For E4, only one CTD was mounted in tank B (a SeaCat SBE19- SN 2161). To convert the measured water conductivity to salinity in grams $\mathrm{NaCl}$ per $\mathrm{kg}$ solution we modified the standard UNESCO algorithms for seawater (Fofonoff and Millard, 1983), with a reference conductivity $45.317 \mathrm{~m} \mathrm{Scm}^{-1}$ for an $\mathrm{NaCl}$ solution of $35 \mathrm{~g} \mathrm{NaCl} \mathrm{kg}^{-1}$ at $15^{\circ} \mathrm{C}$ and atmospheric pressure. From available data (Kaufmann, 1960) we estimate, for our ranges, an uncertainty of $0.05 \mathrm{~g} \mathrm{NaCl} \mathrm{kg}^{-1}$ due to this conversion. The freezing temperature $\left(T_{\mathrm{f}}\right)$ was calculated based on equation A15 from Maus (2007), also given in De la Rosa et al. (2011), with a constant pressure correction of $-0.008 \mathrm{~K}$ for atmospheric pressure and half a meter water depth. This gives $-2.105{ }^{\circ} \mathrm{C}$ for a $\mathrm{NaCl}$ solution of $35 \mathrm{~g} \mathrm{~kg}^{-1}$ salt content.

Table 1 lists the mean values for air temperature, water freezing temperature and the change in water temperature 


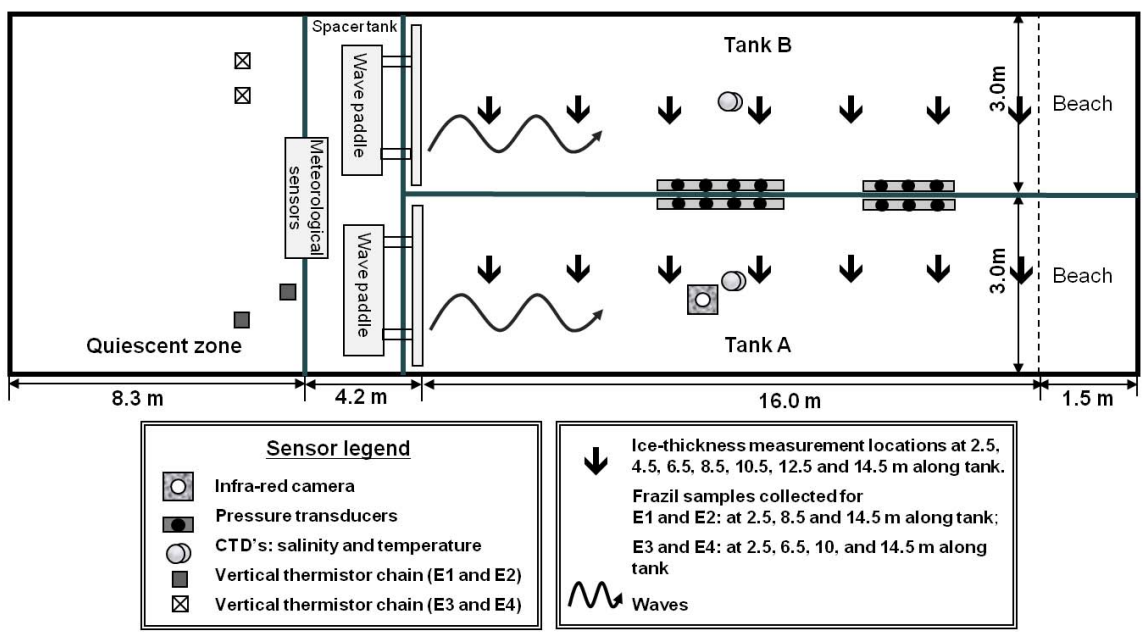

Fig. 1. Top view schema of the laboratory layout (not to scale), modified from Wilkinson et al. (2009) to correct scales and to display instruments relevant to this paper.

and salinity throughout the experiment. The water values are given for the top CTD closest to the growing ice cover. The accuracy of the CTD measurements is better than $0.003 \mathrm{~K}$ in terms of temperature and $0.01 \mathrm{~g} \mathrm{~kg}^{-1}$ in terms of salinity. Considering the uncertainty of $0.05 \mathrm{~g} \mathrm{~kg}^{-1}$ in the conversion from conductivity to salinity plus the uncertainty from the CTD (both errors may be systematic), we get an uncertainty in the salinity of $0.06 \mathrm{~g} \mathrm{~kg}^{-1}$. This implies a freezing temperature uncertainty of $0.06 d T_{\mathrm{f}} / d S \approx 0.004 \mathrm{~K}$. Assuming a similar uncertainty in the algorithm for $\left(T_{\mathrm{f}}\right)$, freezing point deviations are likely correct to within $0.01 \mathrm{~K}$.

\subsection{Ice sampling}

Frazil ice thickness $\left(H_{\mathrm{i}}\right)$ was measured at fixed positions between 2.5 and $14.5 \mathrm{~m}$ along the tank (locations indicated in Fig. 1) and at approximately 1.5-h intervals. Measurements were made from two movable bridges placed across each tank. The frazil ice sampling and thickness measurement procedure was adopted from earlier studies using a plastic cylinder (e.g., Wilkinson, 2005; Smedsrud and Skogseth, 2006). Uncertainties in these observations are of the order of $\pm 0.3 \mathrm{~cm}$. At a subset of the sampling locations (refer to Fig. 1 legend), after measuring ice thickness, in-situ frazil ice samples were collected from the cylinder into a handheld sieve to drain off the water before melting the ice in bottles at room temperature. The electrolytic conductivity of the melted samples was inferred from a hand-held conductimeter (WTW LF 191). The converted ice salt content is accurate to $\pm 0.2 \mathrm{~g} \mathrm{NaCl} \mathrm{kg}^{-1}$. Sample weight and volume were obtained using a standard measuring scale (accurate to $\pm 0.01 \mathrm{~g}$ ) and a volumetric flask (accurate to $\pm 0.1 \mathrm{ml}$ ), respectively. Shuga and pancake samples were also sporadically collected, photographed and their thickness measured.
Size was also measured in the along-tank direction and the across-tank direction. Pancake-like ice began to appear during the average times listed in Table 1.

\subsection{Wave observations}

To record the wave amplitude, two groups of underwater pressure transducers (Omega PX439-005) were placed at the central wall between the tanks. For E1 and E2, they were placed $60 \mathrm{~cm}$ from the tank floor and for E3 and E4 at 45 $\mathrm{cm}$ from the tank floor. Depth differences were corrected accordingly for each experiment. Their positions are marked in Fig. 1, centred at $7.5 \mathrm{~m}$ and $11.5 \mathrm{~m}$ distance from the wave paddles (also see Wang and Shen, 2010a). The wave frequency $(f)$ for each experiment, obtained from the mechanical wave paddle reading, is listed in Table 2. During E1 the same frequency was applied in both tanks and maintained constant. During E2 a different frequency was applied in both tanks, yet also kept constant. The wave amplitude was decreased to $\sim 2.5 \mathrm{~cm}$ during experiment hour 20 . For the last two experiments, frequency was changed: during E3 three frequencies were applied, each of more than $5 \mathrm{~h}$ duration, with corresponding wave periods between 1.1 and $1.5 \mathrm{~s}$. During E4 multiple wave changes were made between periods 0.9 to $2 \mathrm{~s}$, each maintained for a minimum of 3 min up to $50 \mathrm{~min}$. In laboratory studies, the tank size is a strong limitation, so lower wave frequencies (and longer wave lengths) were not applied to get longer wave periods. However, the tanks used for the RECARO project were considerably larger than those used in other published wave studies (e.g. Martin and Kauffman, 1981; Newyear and Martin, 1997). 
Table 1. Experiment properties. Total experiment duration, Start of pancake formation, $\overline{T_{\mathrm{a}}}$ : mean air temperature from $+8 \mathrm{~cm}$ above calm water tank and roof (where available). $\overline{T_{\mathrm{f}}}$ : mean $\mathrm{NaCl}$ solution freezing temperature from top CTD (where available). $\overline{\Delta T_{\mathrm{W}}}$ and $\overline{\Delta S_{\mathrm{W}}}:$ mean change in water temperature and water salinity during experiment duration. $S_{\mathrm{W} 0}$ : initial salinity before ice freezing, measured for E1 and E2 from top CTD data, calculated for E4 (see Sect. 3.5) and estimated for E3 assuming same conditions as in E1. $H_{\mathrm{i}}, S_{\mathrm{i}}$ and $v_{\mathrm{s}}$ : maxima and minima values for frazil ice thickness, salinity and volume fraction data. $\mathrm{STD}_{\overline{H \mathrm{i}}}, \mathrm{STD}_{\overline{\mathrm{Si}}}$ and $\mathrm{STD}_{\overline{v \mathrm{~s}}}$ denote the average variation of variables $H_{\mathrm{i}}, S_{\mathrm{i}}$ and $v_{\mathrm{s}}$ along the tank and are computed as the mean of the standard variations of each sample set in time.

\begin{tabular}{|c|c|c|c|c|c|c|c|c|}
\hline & E1 A & E1 B & E2 A & E2 B & E3 A & E3 B & E4 A & E4 B \\
\hline Duration (h) & 51.7 & 51.7 & 44.3 & 44.3 & 55.4 & 55.4 & 46.4 & 46.4 \\
\hline Pk Start & 17 & 17 & 21 & 19 & 3 to 4 & 3 to 4 & 5 & 5 \\
\hline$\overline{T_{\mathrm{a}}}\left({ }^{\circ} \mathrm{C}\right)$ & \multicolumn{2}{|c|}{$\begin{array}{l}-9.09(+8 \mathrm{~cm}) \\
-10.80(\text { roof })\end{array}$} & \multicolumn{2}{|c|}{$\begin{array}{l}-8.72(+8 \mathrm{~cm}) \\
-10.55 \text { (roof) }\end{array}$} & \multicolumn{2}{|c|}{$-9.16(+8 \mathrm{~cm})$} & \multicolumn{2}{|c|}{$-12.10(+8 \mathrm{~cm})$} \\
\hline$\overline{T_{\mathrm{f}}}\left({ }^{\circ} \mathrm{C}\right)$ & -2.02 & -1.99 & -1.97 & -1.99 & no data & no data & no data & -2.14 \\
\hline$\overline{\Delta T_{\mathrm{W}}}\left({ }^{\circ} \mathrm{C}\right)$ & -0.14 & -0.19 & -0.37 & -0.09 & no data & no data & no data & -0.16 \\
\hline$\overline{\Delta S_{\mathrm{W}}}\left(\mathrm{g} \mathrm{kg}^{-1}\right)$ & 1.42 & 1.78 & 4.10 & 1.23 & no data & no data & no data & 0.71 \\
\hline$S_{\mathrm{w} 0}\left(\mathrm{~g} \mathrm{~kg}^{-1}\right)$ & 33.00 & 33.17 & 31.33 & 33.08 & 33.00 & 33.00 & 35.38 & 35.38 \\
\hline \multicolumn{9}{|c|}{ Frazil ice property ranges } \\
\hline $\begin{array}{l}H_{\mathrm{i}_{\min } \text { to } \max } \\
\mathrm{STD}_{H \bar{i}}(\mathrm{~cm})\end{array}$ & $\begin{array}{r}0.4-12.0 \\
\pm 2.3 \\
\end{array}$ & $\begin{array}{r}0.2-9.4 \\
\pm 2.2 \\
\end{array}$ & $\begin{array}{r}2.5-11.0 \\
\pm 2.8 \\
\end{array}$ & $\begin{array}{r}0.5-13.5 \\
\pm 3.1 \\
\end{array}$ & $\begin{array}{r}0.3-11.1 \\
\pm 2.9 \\
\end{array}$ & $\begin{array}{r}0.3-12.5 \\
\pm 2.9 \\
\end{array}$ & $\begin{array}{r}1.5-6.0 \\
\pm 1.7 \\
\end{array}$ & $\begin{array}{r}2.5-6.5 \\
\pm 1.8\end{array}$ \\
\hline $\mathrm{n}^{\circ}$ samples & 117 & 119 & 56 & 55 & 75 & 75 & 42 & 49 \\
\hline$S_{\mathrm{i}_{\text {max }} \text { to min }}$ & $31.8-22.9$ & $32.3-20.3$ & 29.7-22.1 & 31.4-20.6 & $31.9-24.2$ & $31.1-24.7$ & $30.3-24.2$ & $31.7-25.5$ \\
\hline $\operatorname{STD}_{S \overline{\mathrm{i}}}\left(\mathrm{g} \mathrm{kg}^{-1}\right)$ & \pm 1.05 & \pm 1.37 & \pm 2.02 & \pm 2.96 & \pm 1.88 & \pm 1.47 & \pm 1.02 & \pm 1.22 \\
\hline$v_{\mathrm{S}_{\min }}$ to $\max$ & $0.04-0.35$ & $0.03-0.43$ & $0.15-0.36$ & $0.06-0.41$ & $0.04-0.29$ & $0.06-0.27$ & $0.16-0.34$ & $0.12-0.30$ \\
\hline $\mathrm{STD}_{v \overline{\mathrm{s}}}$ & \pm 0.04 & \pm 0.05 & \pm 0.06 & \pm 0.09 & \pm 0.06 & \pm 0.05 & \pm 0.03 & \pm 0.04 \\
\hline $\mathrm{n}^{\circ}$ samples & 41 & 44 & 19 & 11 & 27 & 31 & 16 & 20 \\
\hline
\end{tabular}

Table 2. Experiment wave properties. $f$ : wave frequencies applied to each tank. $A_{0}$ : incoming amplitude measured at sensor group 1 near wave paddle. $\lambda$ : average wavelength at sensor group 1 .

\begin{tabular}{lccccccrr}
\hline & E1 A & E1 B & E2 A & E2 B & E3 A & E3 B & E4 A & E4 B \\
\hline$f(\mathrm{~Hz})$ & 0.90 & 0.90 & 0.67 & 0.78 & $0.92 ; 0.90 ; 0.67$ & $0.92 ; 0.90 ; 0.67$ & 0.5 to 1.11 & 0.5 to 1.11 \\
\hline$A_{0}(\mathrm{~cm})$ & 2.84 & 3.28 & 4.61 & 5.95 & $3.29 ; 3.78 ; 2.37$ & $3.51 ; 3.63 ; 1.95$ & 1.16 & 0.98 \\
\hline$\lambda(\mathrm{m})$ & 1.92 & 1.92 & 3.28 & 2.49 & $1.84 ; 1.92 ; 3.28$ & $1.84 ; 1.92 ; 3.28$ & 4.95 to 1.27 & 4.95 to 1.27 \\
\hline
\end{tabular}

\section{Observations}

\subsection{Air and water temperature and water salinity}

Figure 2a-d shows, for experiment E1, the time series of air temperature $\left(T_{\mathrm{a}}\right)$, the water and freezing temperature difference $\left(T_{\mathrm{w}}-T_{\mathrm{f}}\right)$ and the water temperature against salinity for both tanks. Observations from the top and bottom CTD (Conductivity-Temperature-Depth) instruments are shown in Fig. 2b-d. All temperature series show a similar behaviour at levels from 0.20 and $0.45 \mathrm{~m}$ from the tank bottom. Within the observational uncertainty $(0.01 \mathrm{~K})$ none of the four instru- ments show supercooling, temperature being slightly above freezing. During the first $5 \mathrm{~h}$ of $\mathrm{E} 1$, the temperature decreased by $\approx 0.1{ }^{\circ} \mathrm{C}$ in the water and by $3.5^{\circ} \mathrm{C}$ in the air, yet ice formation had already begun (the first ice thickness measurement was made a half hour after the beginning of this time series). During experiment hour 9 of E1, a wave paddle stop occurred for $2 \mathrm{~h}$, due to a mechanical problem in both tanks. This caused a warming of the tank water (Fig. 2b and c). Water temperatures decreased again once the wave paddles were restarted an hour later, accompanied by a rise in the air temperature (Fig. 2a). During the first $5-10 \mathrm{~h}$ of 


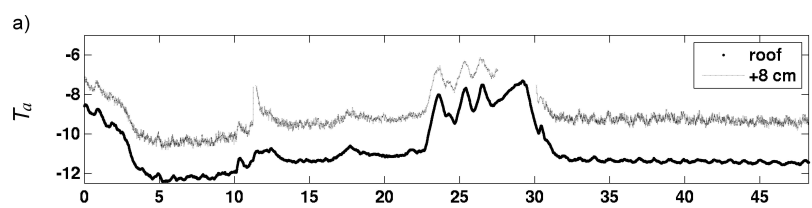

b)
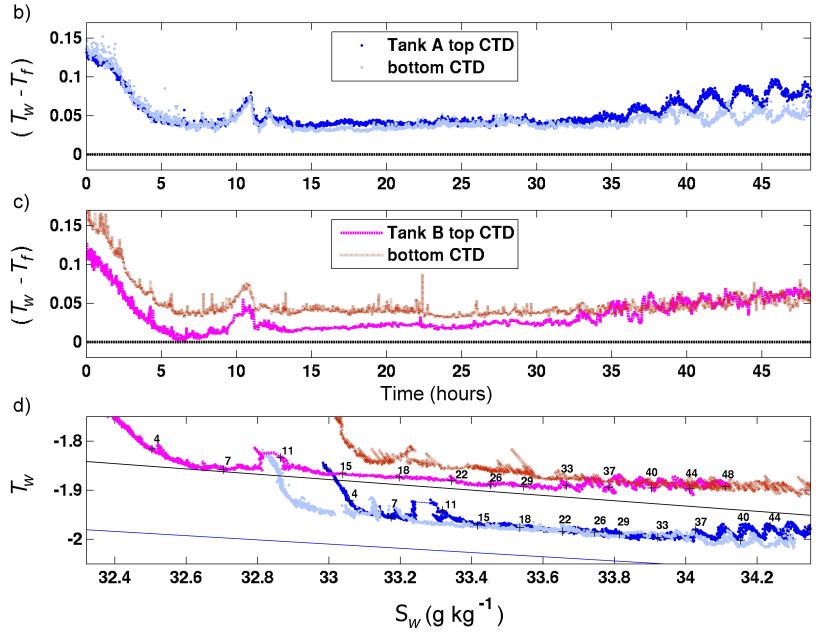

Fig. 2. Air temperatures and CTD data for E1: (a) $T_{\mathrm{a}}$ from $+8 \mathrm{~cm}$ thermometer sensor in quiet tank and roof sensor, (b) and (c) deviation from freezing temperature for both CTD sensors in tanks A and $\mathrm{B}$, respectively, (d) water temperature against salinity for both sensors and tanks. Tank B temperatures (red and pink) were displaced by +0.1 to avoid overlap with tank A data. Solid lines in (d) are the water freezing temperature (black line is displaced +0.1 , to be comparable with tank B curves), while labeled numbers represent time (in hours) for top CTD data in each tank. All temperatures are given in ${ }^{\circ} \mathrm{C}$. $\mathrm{X}$-axis for (a), (b) and (c) represents time. Legends in (b) and (c) also apply to (d).

E2 (not shown), a salinity decrease was measured in tank B while salinity increased in tank A. This stratification dissipated due to wave stirring after $2 \mathrm{~h}$. This could be an indicator that an exchange took place between the tanks and that the isolation between the tanks was not perfect. The tank differences could have also been caused by the melt water refill before the start of E2. The measurement record for E4 (also not shown) started around $2.4 \mathrm{~h}$ after the actual experiment began.

\subsection{Heat flux from surface}

The bulk heat flux through the tank water surface (with or without ice cover) is approximated as:

$Q=H_{\mathrm{w}} C_{\mathrm{pw}} \rho_{\mathrm{w}}\left(-\frac{d T_{\mathrm{w}}}{d t}\right)+\frac{d H_{\mathrm{e}}}{d t} L_{\mathrm{f}} \rho_{\mathrm{i}}\left(\mathrm{W} \mathrm{m}^{-2}\right)$,

where the first term on the right is the heat flux due to cooling $\left(Q_{\mathrm{s}}\right)$ of the water prior to ice formation. This was obtained from the rate of change in water temperatures, $T_{\mathrm{w}}$, measured from the top and bottom CTDs, the water depth, $H_{\mathrm{w}}$, the specific heat capacity of water, $C_{\mathrm{pw}}=4009.0 \mathrm{~J} \mathrm{~kg}^{-1} \mathrm{~K}^{-1}$, and the water density, $\rho_{\mathrm{w}}=1025.9\left(\mathrm{~kg} \mathrm{~m}^{-3}\right)$. The period of cooling was defined as the time when $T_{\mathrm{w}}>=-1.5^{\circ} \mathrm{C}$. The second term in Eq. (1) is the heat flux during frazil ice growth ( $Q_{\mathrm{i}}$ ), with the latent heat of fusion, $L_{\mathrm{f}}=330.7 \mathrm{k} \mathrm{J} \mathrm{kg}^{-1}$, the pure ice density; $\rho_{\mathrm{i}}=917 \mathrm{~kg} \mathrm{~m}^{-3}$ and the equivalent ice thickness, defined as $H_{\mathrm{e}}=H_{\mathrm{i}} v_{\mathrm{s}}$, where $v_{\mathrm{s}}$ is the solid volume fraction of ice. All mentioned thermal properties were evaluated for a $33.3 \mathrm{~g} \mathrm{~kg}^{-1} \mathrm{NaCl}$ solution at the freezing point of $-2.00{ }^{\circ} \mathrm{C}$ following Maus (2007). Their temperature dependence may be neglected compared to uncertainties in the observations. The above equation assumes a uniform rate of change in the tank water temperature and applies for a tank 'perfectly insulated' from all sides except the upper surface and neglecting mass loss by evaporation.

The average $Q_{\mathrm{s}}$ obtained from water temperature differences from the top and bottom CTDs during the initial cooling period, was $81.3 \pm 8.6 \mathrm{Wm}^{-2}$ for tank $\mathrm{A}$ and $81.2 \pm 2.8 \mathrm{Wm}^{-2}$ for tank $\mathrm{B}$. We note that the average value of $Q_{\text {s }}$ obtained from the two CTD sensors in each tank, was very similar, yet, a notably larger variability was observed in tank A than B. This may indicate that the apparent heat flux variability is not related to the heating intervals from the roof cooling plates, but rather to the variability of the water movement itself (e.g. wave-generated residual currents advecting temperature anomalies past the CTD sensors). In Sect. 4.1 we will determine the total heat flux after the freezing point is reached $\left(Q_{\mathrm{i}}\right)$, based on ice growth observations for each experiment. This neglects the small $Q_{\text {s }}$ due to lowering of the freezing temperature that was estimated as less than $0.1 \mathrm{Wm}^{-2}$ (Fig. 2d).

\subsection{Ice Thickness}

For each instant of time we fitted the measured ice thickness distribution $H_{\mathrm{i}}(x)$ along the tank axis $x$ with a power law $\left(H_{\mathrm{i}}=a x^{b}\right)$ and an exponential fit $\left(H_{\mathrm{i}}=a\left(1-e^{(b x)}\right), a\right.$ and $b$ being constants obtained by nonlinear regression. Comparing the fits with the observations we found the exponential to perform much better (mean standard deviation of residuals of $0.49 \mathrm{~cm})$ than the power law $(1.25 \mathrm{~cm})$. It may also be noted that for the power law no stable exponent was found. The exponential fits obtained closest to 5,15 and $25 \mathrm{~h}$ are shown in Fig. 3 along with all thickness observations. In all experiments, with exception of E1 (see also Fig. 4a), it was observed that the along-tank ice thickness distribution became approximately uniform towards the end of the runs. This occurred first during E2 and E4. In the latter experiments ice formation had begun $5-10 \mathrm{~h}$ prior to hour 0 when the first sample was taken. 
Tank A
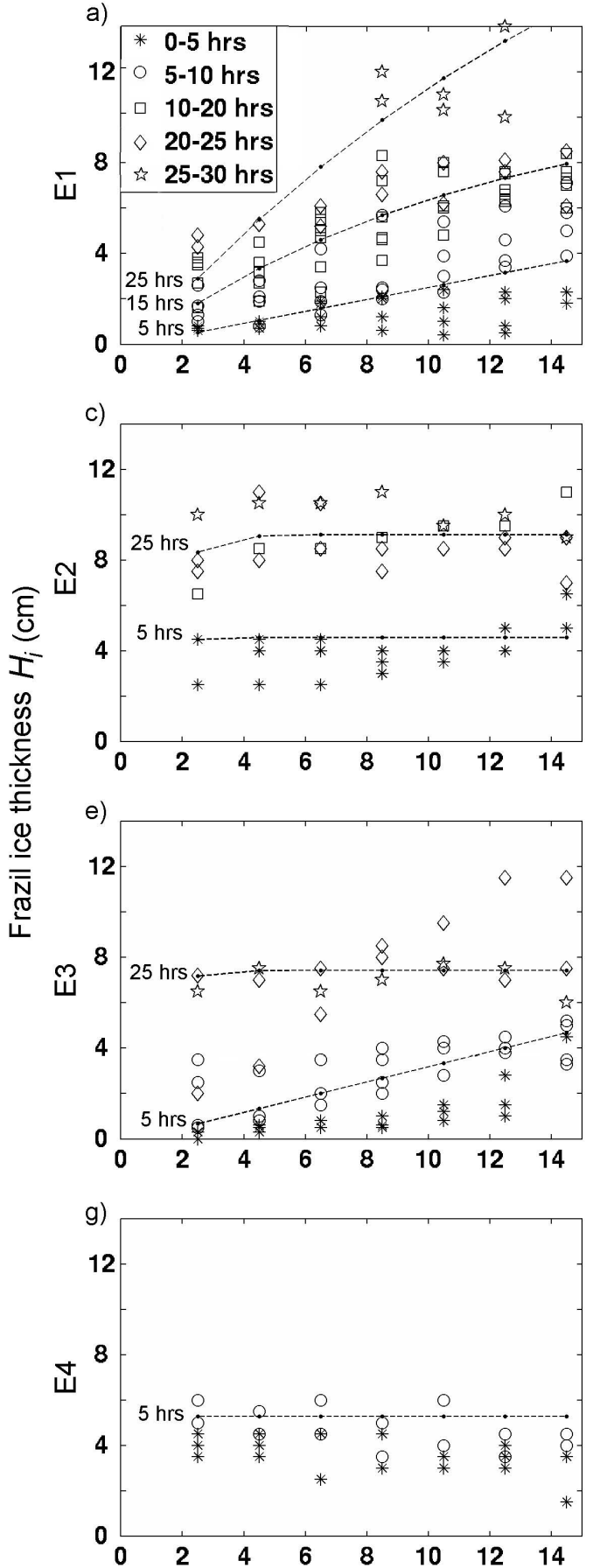

Tank B
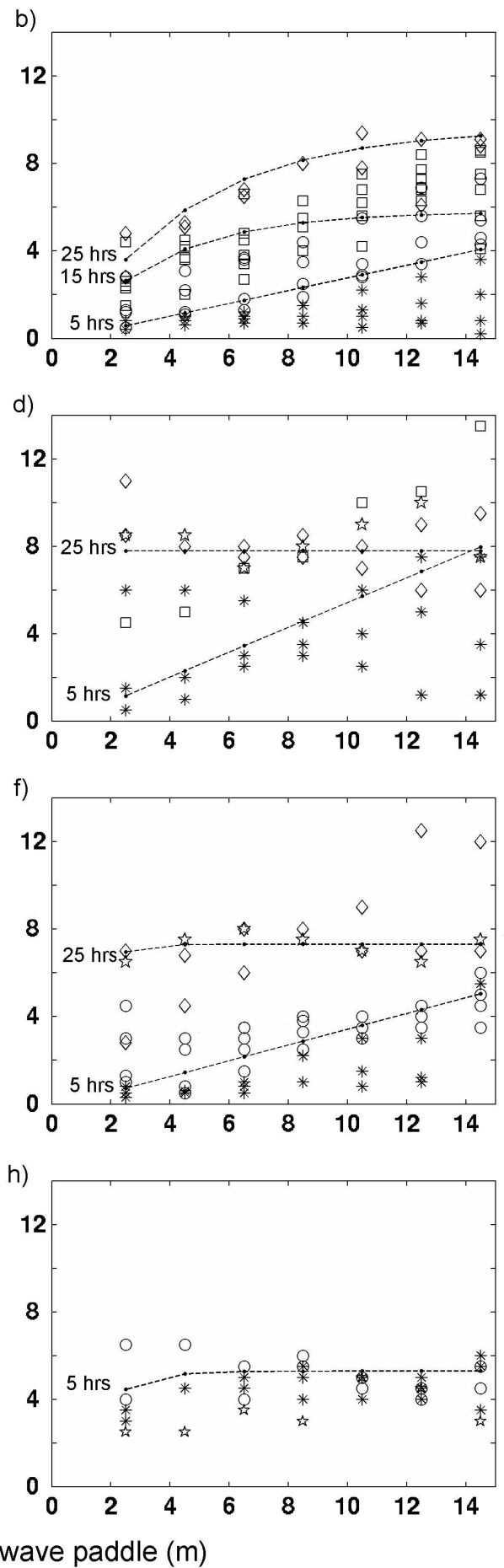

Fig. 3. Frazil ice thickness evolution along the tank for all experiments: (a) and (b) E1, (c) and (d) E2, (e) and (f) E3, (g) and (h) E4. Panels to the left display data from tank A, panels to the right display data from tank B. The dashed lines correspond to mean ice thicknesses (for 5 , 15 and $25 \mathrm{~h}$ where applicable) from the exponential fit discussed in Sect. 3.3. 

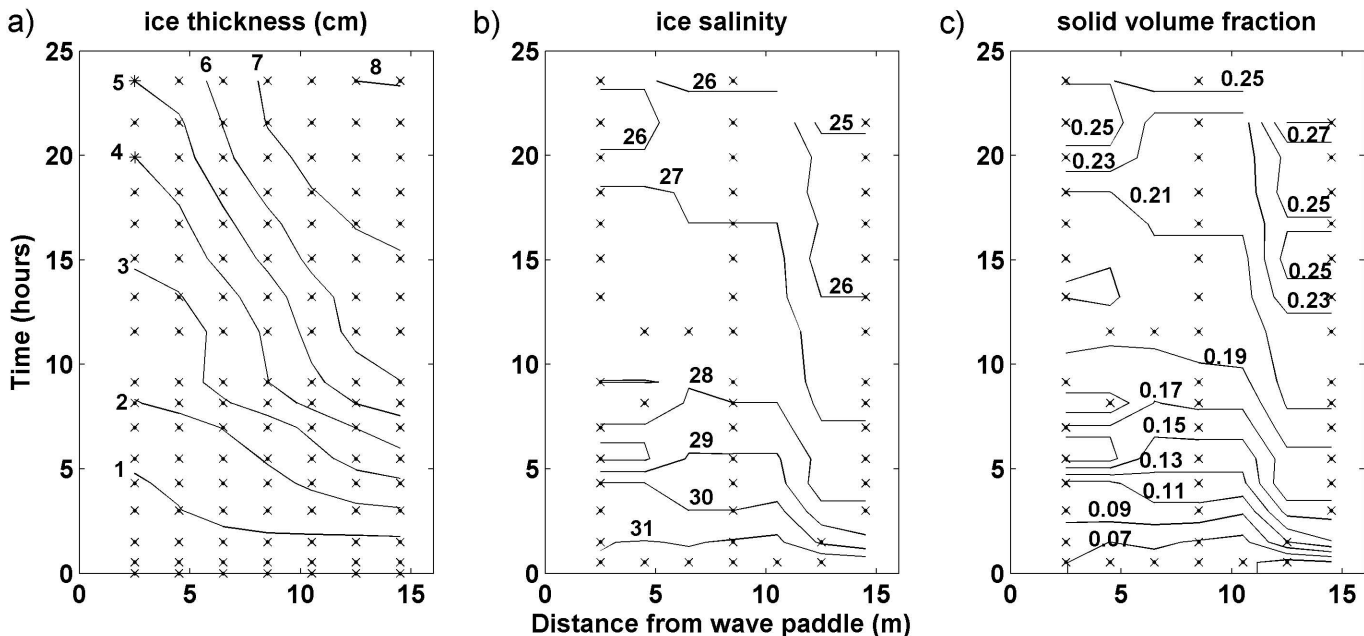

Fig. 4. Contour plot of thickness, salinity and solid fraction for experiment E1, averaging observations from tanks A and B. Crosses indicate the observation locations and times.

\subsection{Frazil ice salinity and solid fraction}

We determine the solid ice volume fraction within the frazil and grease ice from

$v_{\mathrm{s}}=\frac{M_{\mathrm{m}}}{V_{\mathrm{g}} \rho_{\mathrm{i}}}\left(1-\frac{S_{\mathrm{i}}^{\prime}}{S_{\mathrm{b}}}\right)$,

where $V_{\mathrm{g}}$ is the measured frazil/grease ice volume before drainage, $M_{\mathrm{m}}$ the mass and $S_{\mathrm{i}}^{\prime}$ the drained salinity of the collected samples after sieving and melting and $S_{\mathrm{b}}$ the brine salinity. The brine salinity was not directly measured, so we assume $S_{\mathrm{b}}=S_{\mathrm{w}}$. Details on the derivation and application of Eq. (2) are given in Maus and De la Rosa (2012). Resulting $v_{\mathrm{s}}$ values are presented in Sect. 4 . The volume fraction of pancakes cannot be properly determined with this method, as pancakes were broken during sampling, so the exact volume of the sampled pancake pieces before melting, was unknown. For reference, Wang et al. (2008) found large uncertainties when applying this approach for calculating pancake ice volume fractions.

Ice salinities were calculated based on the frazil or grease ice solid volume fraction (thus, correcting for the loss of brine that occurs during frazil and grease ice sampling), using:

$S_{\mathrm{i}}=\frac{S_{\mathrm{b}}}{1-\frac{\rho_{\mathrm{i}}}{\rho_{\mathrm{b}}}\left(1-\frac{1}{\left(1-v_{\mathrm{s}}\right)}\right)}$,

(obtained from mass and salt conservation, Maus 2007; Maus and De la Rosa, 2012). The brine density in the ice was approximated as $\rho_{\mathrm{b}}=1000+0.77 \mathrm{~S}_{\mathrm{b}}$ (see Kaufmann, 1960). Sieved sample salinities, $S_{\mathrm{i}}^{\prime}$, are up to $45 \%$ smaller than the actual in situ undrained salinities. These are presented and addressed further in Maus and De la Rosa (2012).
For experiments E3 and E4 no CTD measurements were available at the beginning of the tests (i.e. the exact initial salinity was not known). For E3, the target value when filling the tank was as for E1. Hence, the value of $S_{\mathrm{w} 0}=33$ was used. In E4, tank B, CTD observations started $2.4 \mathrm{~h}$ after the beginning of the experiment. We thus obtained $S_{\mathrm{w}}$ for the initial period from the heat loss $Q_{\mathrm{s}}$ via $S_{\mathrm{w} 0}$, the initial water salinity before ice formation, required for estimating ice production and the change in $S_{\mathrm{w}}$, by iteration in time as:

$S_{\mathrm{w}(t)}=-\frac{Q_{\mathrm{s}}}{L_{\mathrm{f}} \rho_{\mathrm{i}}} \frac{S_{\mathrm{w}(t)} \Delta t}{H_{\mathrm{w}}}+S_{\mathrm{w}(t+1)}$,

where $\Delta t$ is the timestep between the salinity measurements, obtained from the mass and salt balance. The higher initial salinity $S_{\mathrm{w} 0}$ for E4 ( 35.4 as given in Table 1$)$ may be explained by the removal of ice from E3, which reduced the volume in the tank.

Once $S_{\mathrm{i}}$ was calculated, the mean frazil ice salinity was determined summing all measurements along the tank at any time instant as:

$\overline{S_{\mathrm{i}}}=\frac{\sum S_{\mathrm{i}} H_{\mathrm{i}}}{\sum H_{\mathrm{i}}}$.

The other ice properties $\left(\overline{v_{\mathrm{s}}}\right.$ and $\left.\overline{H_{\mathrm{e}}}\right)$ were also computed using this averaging method. Table 1 lists the maximum and minimum ice salinity that was measured in each experiment and tank.

In our method, the main random error in the determined solid fraction comes from the uncertainty in frazil thickness $( \pm 0.3 \mathrm{~cm})$ read from the sampler, from which $V_{\mathrm{g}}$ is computed. In terms of $v_{\mathrm{s}}$ this implies maximum errors of 0.05 in the beginning of the experiment when the ice thickness is small. Typical errors however decrease after a few hours from $0.02-0.03$ to values close to 0.01 , which then remain for most of the time. This solid fraction error translates into 

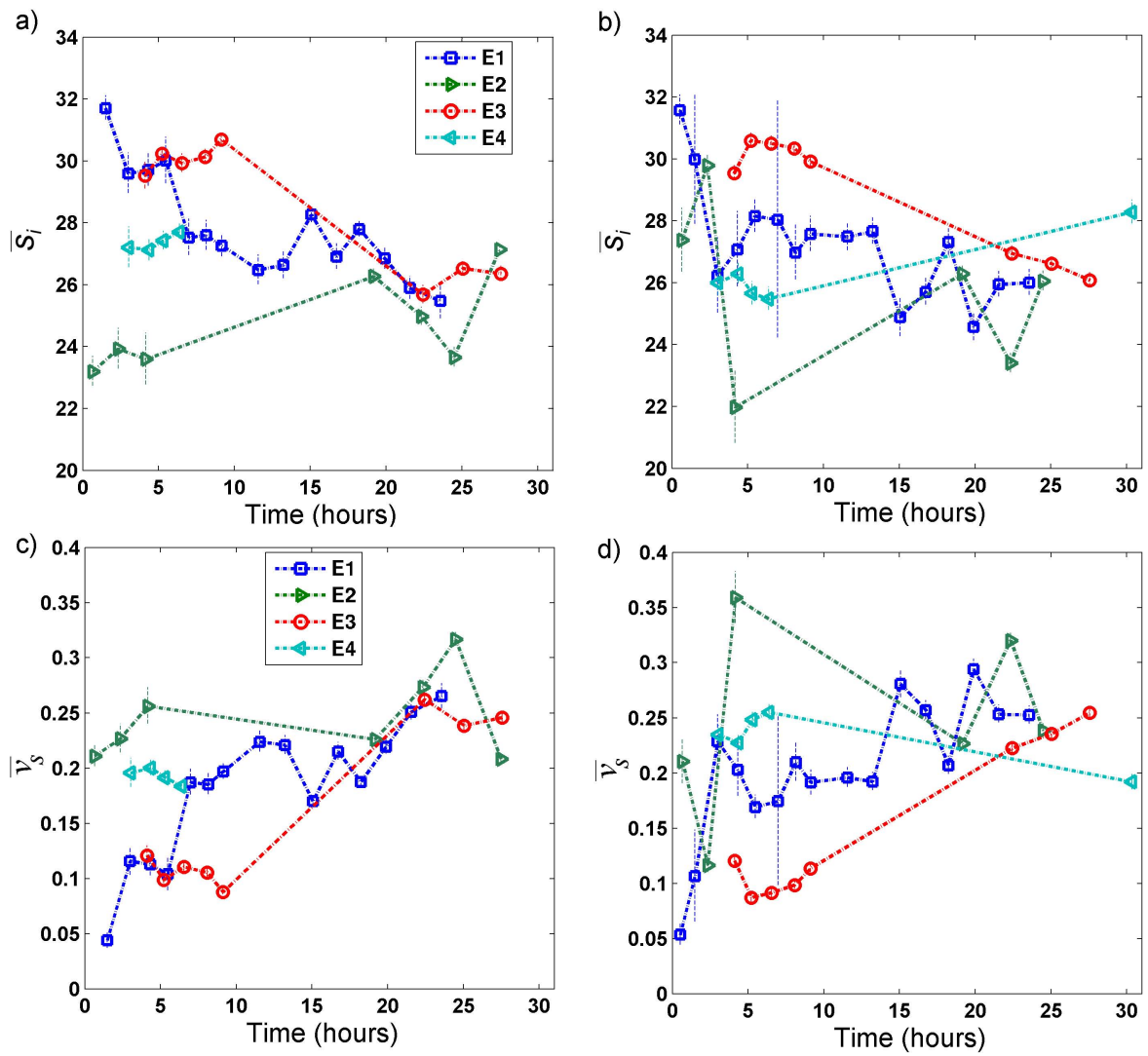

Fig. 5. Time evolution of the thickness-weighted mean frazil ice salinity (thick dashed lines, derived from Eq. 5) for all experiments (a) tank $\mathrm{A}$, (b) tank B as well as mean frazil ice volume fraction (c) tank A, (d) tank B. Note that all salinities in E4 started with $2 \mathrm{~g} \mathrm{~kg}^{-1}$ higher salinity and are therefore normalized by $33 / 35.38$ to allow comparison. Thin vertical lines indicate the standard error of the tank average, assuming a $0.3 \mathrm{~cm}$ maximum uncertainty in ice thickness measurements.

a maximum bulk ice salinity error of $2 \mathrm{~g} \mathrm{~kg}^{-1}$ at the beginning of the experiment, as well as more typical uncertainties of $0.5-1 \mathrm{~g} \mathrm{~kg}^{-1}$ during the first $5 \mathrm{~h}$ and $0.3-0.5 \mathrm{~g} \mathrm{~kg}^{-1}$ on average. The solid fraction is further affected by a second error source related to the assumption $S_{\mathrm{b}}=S_{\mathrm{w}}$, as discussed in Maus and de la Rosa (2012). Observations of young grease ice, while limited (see Reimnitz et al., 1993 for one of the few observations), do indicate that the brine salinity may typically exceed the water salinity by 1 to $2 \mathrm{~g} \mathrm{~kg}^{-1}$, corresponding to an underestimate in the solid fraction per brine salinity difference, $d v_{\mathrm{s}} / d S_{\mathrm{b}}$ of $M_{\mathrm{m}} S_{\mathrm{i}}^{\prime} / V_{\mathrm{g}} \rho_{\mathrm{i}} S_{\mathrm{b}}^{2}$, in $\mathrm{g} \mathrm{kg}^{-1}$. For our observations, $2 \mathrm{~g} \mathrm{~kg}^{-1}$ higher $S_{\mathrm{b}}$ compared to $S_{\mathrm{w}}$ implies an underestimate of $v_{\mathrm{s}}$ by 0.02 at the beginning of the experiments, decreasing to 0.015 at the end. Note that the derived grease ice salinity, $S_{\mathrm{i}}$ (from Eq. 3), increases typically by 1.0 to 1.1 , when assuming a $2 \mathrm{~g} \mathrm{~kg}^{-1}$ higher brine salinity.

\section{Results}

Figure 4 shows the temporal and spatial change in ice thickness, salinity and solid volume fraction for all data obtained during E1. Average bulk ice salinities obtained from Eq. (4) for all experiments are shown in Fig. 5a, b. Salinities in E4 that started with a $2 \mathrm{~g} \mathrm{~kg}^{-1}$ higher water salinity, are shown normalised by 33/35.38, the ratio of initial water salinities. For experiments E1 and E3 salinities are decreasing from values of $29-32 \mathrm{~g} \mathrm{~kg}^{-1}$ during the first 5 to $10 \mathrm{~h}$ to a range $24-28 \mathrm{~g} \mathrm{~kg}^{-1}$ for the remaining $20 \mathrm{~h}$. In experiments E2 and $\mathrm{E} 4$, where no sampling was done during the first $5-10 \mathrm{~h}$ of ice formation, salinities are from the beginning of sampling in this lower range, with no significant trend visible. Figure $5 \mathrm{c}$, $\mathrm{d}$ shows the corresponding weighted mean solid volume fraction values. An increase from initial values below 0.1 to the range $0.2-0.3$ by the end of the experiment is seen in E1 and E3, whereas E2 and E4 are lacking the initial low solid fractions.

Looking at the $S_{\mathrm{i}}$ and $v_{\mathrm{s}}$ histogram distributions of all frazil data (Fig. 6a and b, respectively), we distinguish two main modal peaks, which reflect (I) the first $10 \mathrm{~h}\left(v_{\mathrm{s}} \approx 0.08\right.$ to 0.12 and $S_{\mathrm{i}} \approx 29$ to $31 \mathrm{~g} \mathrm{~kg}^{-1}$ ) and (II) the later stage of the experiments ( $v_{\mathrm{s}} \approx 0.18$ to 0.26 and $S_{\mathrm{i}} \approx 26$ to $28 \mathrm{~g} \mathrm{~kg}^{-1}$ ). When only E2 and E4 are considered (light shades within Fig. 6), the early mode (I) of high salinity and low solid 
a)

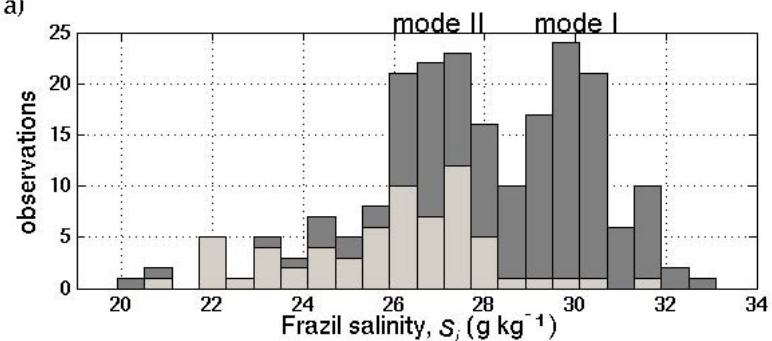

b)

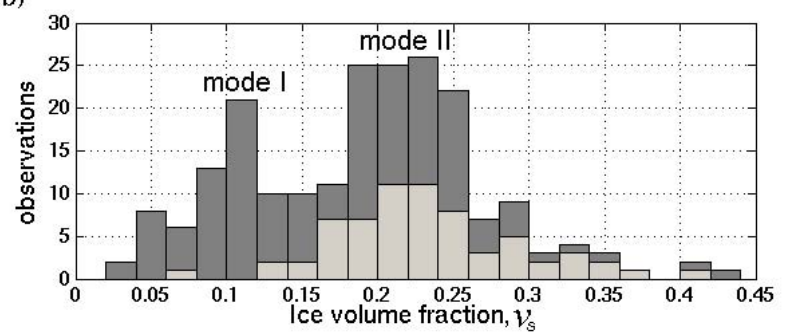

Fig. 6. Histograms for all experiment observations of (a) ice salinity centred in $0.6 \mathrm{~g} \mathrm{~kg}^{-1}$ bins and (b) frazil ice solid fraction, centred in 0.02 bins. Light gray distributions show data from E2 and E4 only.

fraction is absent, due to the already mentioned late start of sampling, 5-10 h after the actual initiation of ice formation. Scrutiny of the time series (Fig. 5) also confirms this interpretation.

\subsection{Equivalent ice thickness}

In laboratory conditions, with relatively constant air ventilation and radiation, the heat flux leading to ice growth may be approximated by the empirical growth law $Q=k_{\mathrm{a}}\left(T_{\mathrm{a}}-T_{\mathrm{s}}\right)$, where $T_{\mathrm{a}}$ is the air temperature at a fixed reference level above the ice, $T_{\mathrm{s}}$ the ice or water surface temperature and $k_{\mathrm{a}}$ a heat transfer coefficient. For the freezing period, in case of a constant heat flux, $Q$ may be obtained from a linear fit of the equivalent ice thickness against time: $\left(\overline{H_{\mathrm{e}}}=\overline{H_{\mathrm{e} 0}}+q_{\mathrm{h}} t\right)$. For the constant heat flux assumption to be valid, we apply this for the periods when mostly frazil ice was present $(t<25 \mathrm{~h}$ for E1 to E3 and $t<6 \mathrm{~h}$ for E4). From the fitted coefficient $q_{\mathrm{h}}$ one then obtains the heat flux for each experiment as $Q_{\mathrm{i}}=q_{\mathrm{h}} L_{\mathrm{f}} \rho_{\mathrm{i}}$.

Figure $7 \mathrm{a}, \mathrm{b}$ show the observed mean $\overline{H_{\mathrm{e}}}$ and corresponding linear fits to obtain $Q_{\mathrm{i}}$. For E2 and E4 the presence of ice at beginning of the experiments is clearly seen (with initial values of 0.4 to $0.8 \mathrm{~cm}$ respectively), yet the linear slopes defining the ice growth rate and heat flux are similar to those of E1 and E3. The negative intercept in E3 needs to be viewed in connection with the relatively low confidence due to only a few observations.

Figure 8 summarises the $Q_{\mathrm{i}}$ values for each experiment and tank, with their corresponding upper and lower $95 \%$ confidence interval limits shown versus the (temporally av- eraged) temperature difference $T_{\mathrm{a}}-T_{\mathrm{s}}$. Also shown is the value $Q_{\mathrm{s}} \sim 82 \mathrm{Wm}^{-2}$ that was determined during the cooling phase in E1. For this value, as well as $Q_{\mathrm{i}}$ in E1, we have the highest confidence.

Estimating the exchange coefficient from the cooling period, $k_{\mathrm{a}}=Q_{\mathrm{s}} /\left(T_{\mathrm{a}}-T_{\mathrm{s}}\right)=8.8 \mathrm{~W} \mathrm{~m}^{-2} \mathrm{~K}^{-1}$, we can compare the latter equation to the different $Q_{\mathrm{i}}$ and $T_{\mathrm{a}}-T_{\mathrm{S}}$ conditions during ice growth. Observations, especially those with lowest uncertainty, are in reasonable agreement with the dashed line.

\subsection{Wave height and ice thickness}

Grease ice accumulation is driven by wave-induced drift and the radiation stress from the waves (Martin and Kauffman, 1981). Being interested in the question at which ice thickness wave damping will affect the accumulation, we computed the attenuation rate, $q$, of the waves similarly to Wadhams et al. (1988) or Newyear and Martin (1997):

$A_{2}=A_{1} e^{-q \Delta_{x}}$,

where $A_{1}$ and $A_{2}$ are the measured wave amplitudes at two locations in the tank separated by $\Delta_{x}=4 \mathrm{~m}$ (taking the central location at each sensor group). We use the mean wave amplitude of each sensor group to reduce noise caused by the individual sensors. To illustrate the relationship of attenuation rate $q$, wave height $\mathrm{w}_{h}$ and ice thickness, we normalise the ice thickness by the initial (open water) wave height $\mathrm{w}_{h 0}$ (i.e. twice the initial wave amplitude $A_{0}$ listed in Table 2). Figure $9 \mathrm{a}$ shows $\mathrm{w}_{h}$ against the normalized ice thickness, $H_{\mathrm{i}} / \mathrm{w}_{h 0}$, for E1. Initially and while the grease ice layer is still thin, $\mathrm{w}_{h}$ remains constant in both tanks. After some scatter in connection with the described stop and restart of the wave paddles $\mathrm{w}_{h}$ begins to decay sharply once $H_{\mathrm{i}}>0.9 \mathrm{w}_{h 0}$ in tank $\mathrm{A}$, or $H_{\mathrm{i}}>0.7 \mathrm{w}_{h 0}$ in tank B. Figure $9 \mathrm{~b}$ shows the corresponding evolution of the spatial attenuation rate with $H_{\mathrm{i}} / \mathrm{w}_{h 0}$, for experiments $\mathrm{E} 1$ and E2. It is observed that $q$ begins to increase above the noise level as $H_{\mathrm{i}}>0.5-0.6 \mathrm{w}_{h 0}$. Above $H_{\mathrm{i}}>0.7-0.9 \mathrm{w}_{h 0}$ there is a considerable increase in the wave attenuation.

Wave reflections are expected to vary with ice thickness and tank geometry in a complex manner, see Wang and Shen $(2010 \mathrm{a}, \mathrm{b})$. Yet, the length $(L)$ of the tank is its natural scale of damping and resonance. For the present tanks, where waves are created on one and strongly dissipated on the other end ("beach"), we may think of $L$ as a forced damping scale of the tank. This natural scale of the tank, $1 / L$, is plotted in Fig. $9 \mathrm{~b}$ as a continuous dashed line to indicate the level below which the estimated $q$ may be interpreted in this way. In both experiments $\mathrm{E} 1$ and $\mathrm{E} 2$, the initial $q$ values for tank A (diamonds) are a factor of $2-4$ smaller than the $1 / L$ tank scale, while in tank B they are close to it. In Fig. 9c we thus illustrate the observations by normalising $q$ by the apparent average noise level from the two tanks. We see that in both tanks, $q$ begins to rise above the apparent noise level when 

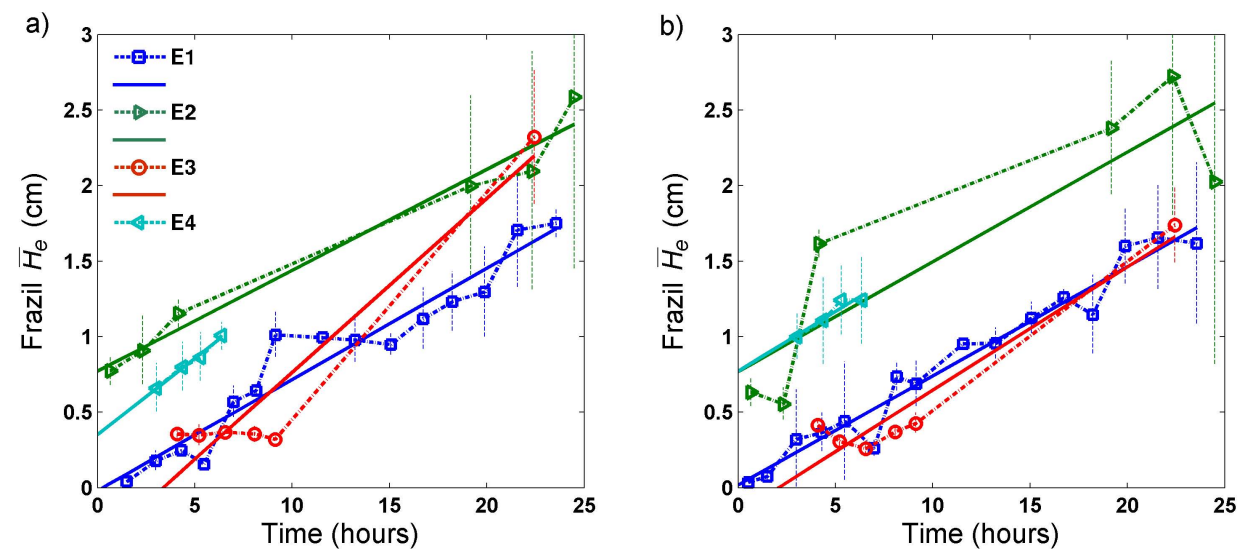

Fig. 7. Mean equivalent ice thickness $\overline{H_{\mathrm{e}}}$ spatially averaged over the tank (thick dashed lines) and corresponding linear regressions to estimate $Q_{\mathrm{i}}$ (thick solid lines). Panel (a) corresponds to tank A, panel (b) to tank B. Thin vertical lines indicate the standard error of the mean, estimated from the difference of the measured and fitted ice thickness (shown in Fig. 3) times the thickness-weighted mean volume fraction (shown in Fig. 5c,d).

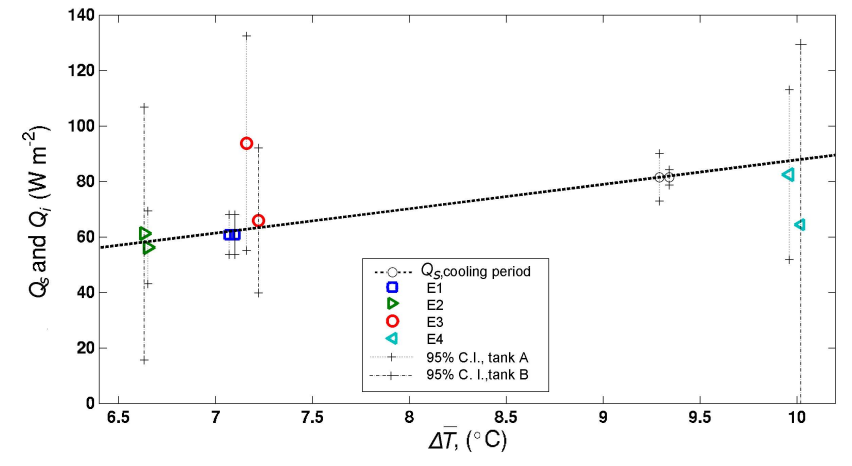

Fig. 8. Variation of derived heat fluxes $\left(Q_{\mathrm{s}}\right.$ during cooling and $Q_{\mathrm{i}}$ during ice growth) with temporally averaged temperature difference between water and air (at $+8 \mathrm{~cm}$ height) for each experiment and tank. Upper and lower $95 \%$ confidence intervals (according to linear regressions in Fig. 7) are given with vertical black lines: tank A (dotted) and tank B (dash dot). Tank B points for the cooling period, E3 and E4, have been displaced in the $\mathrm{x}$-axis by +0.06 units, for visibility. The heavy dashed line is the linear growth law calculated from the cooling period heat flux as described in Sect. 4.1.

$H_{\mathrm{i}} / \mathrm{w}_{h 0}$ becomes larger than $0.5-0.6$, with a strong increase in the range 0.7-0.9.

The wave data for E3 (not shown) did not resolve any response of attenuation rate and wave height with the normalized ice thickness growth, since only three data patches were visible, corresponding to the times the wave frequency was changed. For E4 (also not shown), the data values are scattered, yet high $q$ values already occur after experiment hour 2. The experiment was also characterized by a solid pancake layer already forming after just $6 \mathrm{~h}$ of freezing, and in contrast with E2, the ice cover evolved into a solid layer and showed no gaps between pancakes.
Finally we note that, by the end of E1 to E3, the normalized grease ice thickness was between $1.5<H_{\mathrm{i}} / \mathrm{w}_{h 0}<2$ and still increasing, not having reached a limiting value. During E4 however, $H_{\mathrm{i}} / \mathrm{w}_{h 0}$ values close to 3 were reached, before the ice started to consolidate. For E1 to E3 the ice first surpassed the, apparently critical, ice thickness to wave height ratio $H_{\mathrm{i}} / \mathrm{w}_{h 0}>1$ at the end of the tank, after about $12 \mathrm{~h}$ (not shown). As freezing continued, this limiting ratio extended towards locations nearer to the wave paddle. As the nonuniform thickness distribution and the tank geometry both influence the damping behaviour, the present results should be viewed with caution in terms of absolute $q$ and its validity for unconfined natural conditions.

\subsection{Frazil ice compaction rate}

We evaluated the data in terms of a simple packing law, where we assume that the rate by which the solid fraction approaches a maximum value $v_{\mathrm{s}_{\max }}$ is given by $d\left(v_{\mathrm{s}_{\max }}-v_{\mathrm{s}}\right) / d t \approx c_{1}\left(v_{\mathrm{s}_{\max }}-v_{\mathrm{s}}\right)$ for $v_{\mathrm{s}}<v_{\mathrm{s}_{\max }}$. Making this assumption leads to the following exponential relation:

$\overline{v_{\mathrm{s}}}(t)=v_{\mathrm{s}_{\max }}-\left(v_{\mathrm{s}_{\max }}-v_{\mathrm{s} 0}\right) e^{\left(-\frac{t}{t_{c}}\right)}$,

where $v_{\mathrm{S} 0}$ is the solid fraction at $t=0$ and $t_{c}=-1 / c_{1}$. The latter equation describes the evolution of the average solid fraction of a fixed grease ice cover with time. However, it does not consider the aspect that new frazil continuously accumulates on the underside of the existing grease layer. To approximate this process we make a second approach, $d\left(v_{\mathrm{s}_{\max }}-v_{\mathrm{s}}\left(z_{\mathrm{e}}\right)\right) / d z_{\mathrm{e}} \approx c_{2}\left(v_{\mathrm{s}_{\max }}-v_{\mathrm{s}}\left(z_{\mathrm{e}}\right)\right)$, where $z_{\mathrm{e}}$ is the cumulative equivalent thickness measured upwards from the lower grease ice boundary, with the solution:

$v_{\mathrm{s}_{(\mathrm{ze})}}=v_{\mathrm{s}_{\max }}-\left(v_{\mathrm{s}_{\max }}-v_{\mathrm{s} 0}\right) e^{\left(-\frac{z_{\mathrm{e}}}{H_{C}}\right)}$, 

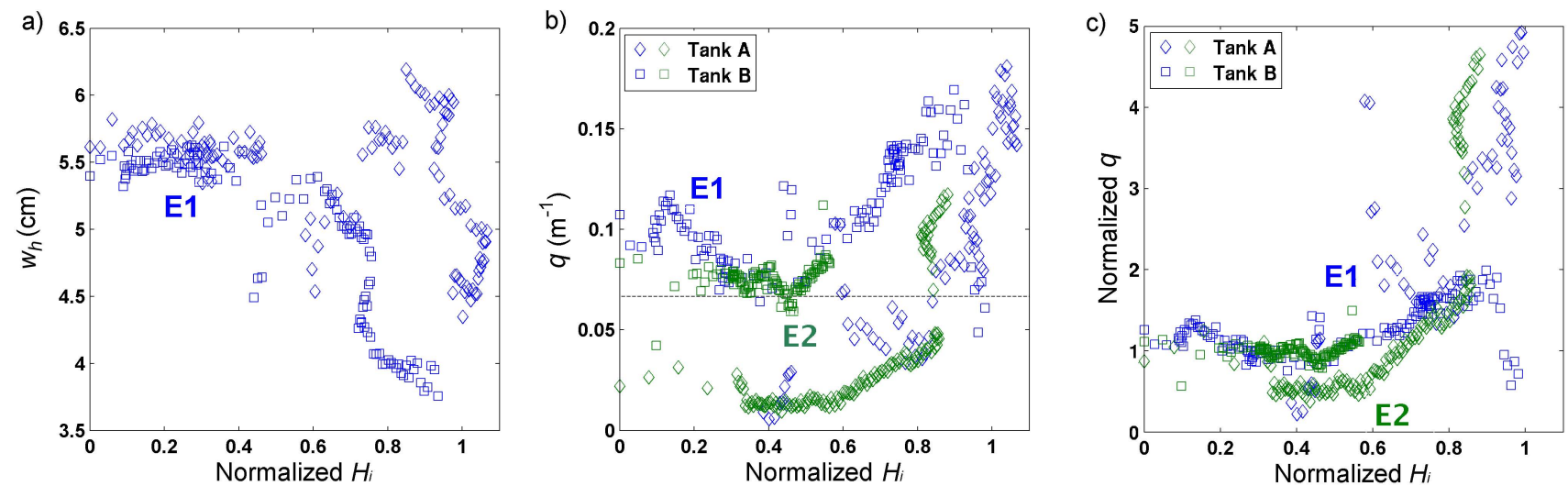

Fig. 9. Scatter plot of (a) wave height (b) attenuation rate and (c) normalized attenuation rate against the mean normalized ice thickness. (a) Displays data for E1 only (b) and (c) show data for E1 (blue) and E2 (green). Squares represent data for tank A, diamonds represent data for tank B. Wave height and ice thickness data from both sensor groups were averaged before plotting. The dashed black horizontal line in (b) is the natural scale of the tank $(1 / L)$.

wherein $H_{c}=-1 / c_{1}$ and $v_{\mathrm{s} 0}$ is the solid fraction at $z_{\mathrm{e}}=0$. Integrating this last equation from the boundary to the top $z_{\mathrm{e}}=H_{\mathrm{e}}$, one obtains a solution for the average solid fraction:

$\overline{v_{\mathrm{s}}\left(H_{\mathrm{e}}\right)}=v_{\mathrm{s}_{\max }}-\left(\frac{H_{c}\left(v_{\mathrm{s}_{\max }}-v_{\mathrm{s} 0}\right)}{H_{\mathrm{e}}}\right)\left(1-e^{-\frac{H_{\mathrm{e}}}{H_{c}}}\right)$.

We then perform a nonlinear least square fit of the data to Eq. (9) for different $v_{\mathrm{s}_{\max }}$ (from 0.1 to 0.5 ) and determine the solution that minimizes the square of the residuals. The approach gives estimates of $v_{\mathrm{S}_{\max }}, v_{\mathrm{s} 0}$, and $H_{c}$ based on the simple compaction model (Eq. 7). Values $v_{\mathrm{s}}>0.30$ were not included in the analysis, assuming that these are frazil samples that had begun to freeze internally.

While Eq. (7) describes how the solid fraction increases locally by accumulation (due to buoyancy) of frazil underneath, Eq. (9) describes the average solid fraction, of which we have observations. Equation (7) thus gives the maximum solid fraction at the surface of ice of equivalent thickness $z_{\mathrm{e}}=H_{\mathrm{e}}$. Figure 10a, $\mathrm{b}$ shows these model fits using $v_{\mathrm{S}}<0.30$ data from all experiments $\mathrm{E} 1$ to $\mathrm{E} 4$, and for $\mathrm{E} 1$ alone. A $v_{\mathrm{s} 0}$ of 0.04 and 0.03 is obtained, respectively and a $v_{\mathrm{s}_{\max }}$ of 0.28 and 0.24 . The exponential decay thickness $H_{c}$ is the value at which $1-e^{-1} \approx 63 \%$ of the maximum packing is achieved. The corresponding $95 \%$ packing (given at $1-e^{-3}$ ) is $3 H_{c}=0.99 \mathrm{~cm}$ for all data and $0.42 \mathrm{~cm}$ for E1. The exclusion of observations above $v_{\mathrm{s}}>0.30$ was a tentative cut-off. However, we argue that observations of higher solid fractions, which occur at all times and appear exceptional, in particular at lower thicknesses, probably do not resemble the average compaction. We did carry out the fit without excluding any samples; this results in $v_{\mathrm{s} 0}=0.05$, $v_{\mathrm{S}_{\max }}=0.31$ and $3 H_{c}=1.2 \mathrm{~cm}$, for all data $\mathrm{E} 1$ to $\mathrm{E} 4$ and for $\mathrm{E} 1$ alone, $v_{\mathrm{s} 0}=0.05, v_{\mathrm{s}_{\max }}=0.27$ and $3 H_{c}=0.57 \mathrm{~cm}$ are obtained. For the fit of $v_{\mathrm{s}}$ versus time (Eq. (6), Fig. 10c), we obtain $v_{\mathrm{s} 0}=0.04, v_{\mathrm{s}_{\max }}=0.23$ and a $95 \%$ packing time scale of about $3 t_{c}=18 \mathrm{~h}$, when only data $v_{\mathrm{s}}<0.30$ are considered, while the results for all solid fractions are $v_{\mathrm{s} 0}=0.04$, $v_{\mathrm{s}_{\max }}=0.25$ and $3 t_{c}=21 \mathrm{~h}$.

\subsection{Pancake formation}

The approximate start time of pancake-like ice formation is given in Table 1. Thickness and diameter observations were made for sporadically sampled pancakes in each tank after these times. Diameter measurements were subdivided according to size into shuga $(<=5 \mathrm{~cm})$ and medium sized pancakes $(>5 \mathrm{~cm})$. Very few observations $(<15)$ were made during E1 and E2, so these are not considered representative for the full tanks. The mean shuga diameter observed during all experiments (estimated from 106 observations) was $1.5 \pm 1.0 \mathrm{~cm}$. The average medium sized pancakes measured during E3 were $15 \pm 9 \mathrm{~cm}$, those measured during E4 were $21 \pm 12 \mathrm{~cm}$ (estimated from 25 and 80 observations, respectively).

If we consider the distribution of sizes along the tank (not shown), during E3, medium sized pancakes were observed only after $9 \mathrm{~h}$ of experiment start and were more abundant between $8 \mathrm{~m}$ to $14 \mathrm{~m}$ away from wave paddle. On the other hand, during E4, the along-tank pancake size distribution was much less defined. Medium sized pancakes were observed everywhere along the tank, from $6 \mathrm{~h}$ into the experiment. A comparison of the pancake thickness $\left(H_{\mathrm{i} p k}\right)$ with frazil thickness $H_{\mathrm{i}}$ from $\mathrm{E} 3$ and $\mathrm{E} 4$, indicated that on average, the maximum pancake thickness was $20-40 \%$ lower than the average frazil thickness. An approximate relation of maximum pancake thickness $H_{\mathrm{i}_{p k}}=\frac{2}{3} H_{\mathrm{i}}$ is determined from these observations. 


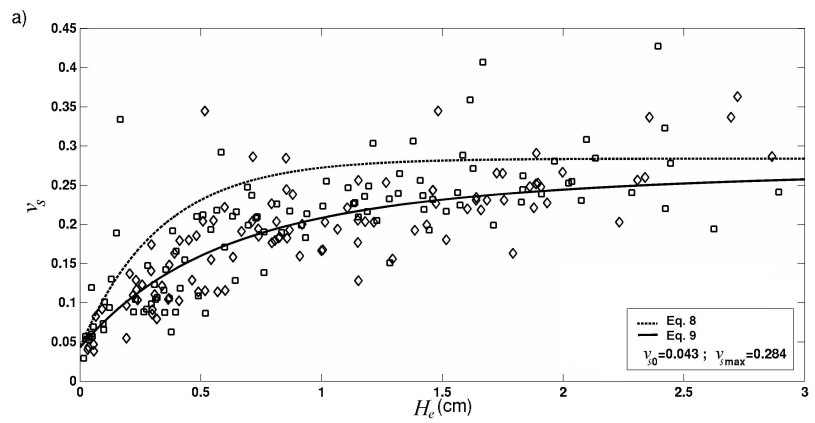

b)

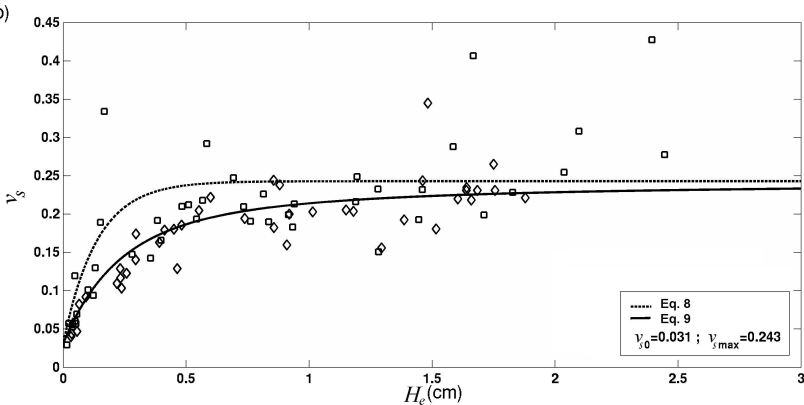

c)

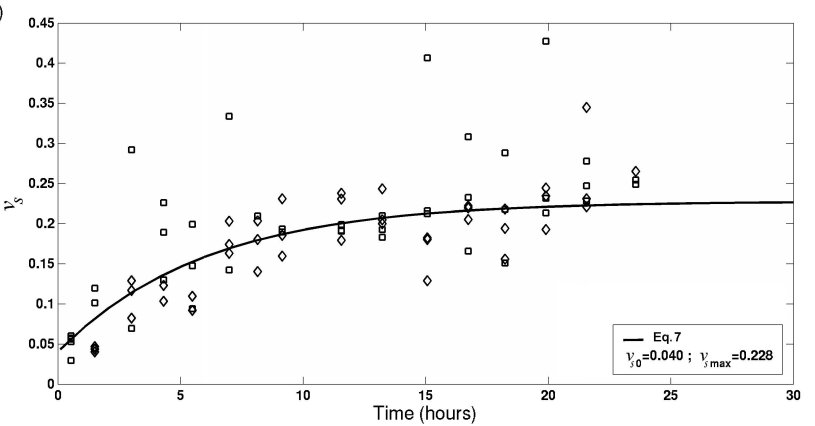

Fig. 10. Frazil volume fraction $v_{\mathrm{s}}$ against equivalent frazil ice thickness $H_{\mathrm{e}}$ : for (a) all experiment observations and (b) for E1. In (c) $v_{\mathrm{S}}$ is shown for $\mathrm{E} 1$ against time, limited to $30 \mathrm{~h}$ growth. In each figure the solid curve shows the best fit of the exponential relations Eq. (7) (c) and Eq. (9) (a and b) to the data. The dashed curve in (a) and (b) is the corresponding Eq. (8), giving the maximum (surface) solid fraction implied by the compaction model. Observations for tank $\mathrm{A}$ are shown as squares, tank B as diamonds.

\section{Discussion}

We have presented results from a laboratory study on the growth of frazil ice under the presence of waves. Our main focus was to monitor the properties of frazil ice, i.e. its salinity, solid ice volume fraction and thickness, as they evolve with time. To do so we estimated these properties with temporal resolution of a few hours and at 7 evenly spaced positions horizontally along the tank. Supplementary observations to interpret the ice cover evolution include (i) water conductivity/salinity and temperature monitored near the tank's centre, (ii) the wave amplitude and its decay, as well as (iii) air temperatures at different vertical levels above the ice/water surface. While the same laboratory facility has been used earlier to study frazil ice growth in a similar setup (Wilkinson, 2005), the present observations constitute, in terms of temporal and spatial resolution, a unique dataset of frazil ice observations under controlled growth conditions. In addition, we have introduced a number of practical and theoretical improvements on earlier work.

All experiments proceeded under very similar heat flux forcing, in principle in the following way: once the freezing point was reached, frazil began to form over the whole surface of the tank but was accumulated at the 'down-wave' end of the tank, presumably due to wave-induced Stokes drift. Once the "down-wave" thickness approached one to two times the wave height, it did not appear to increase much further, yet from then on a wedge propagated "up-wave", soon filling up the tank with a similar ice thickness. Pancake formation was observed at different times for two experiment groups (after $17-21 \mathrm{~h}$ for $\mathrm{E} 1$ and E2 compared to $3-5 \mathrm{~h}$ for E3 and E4), nevertheless, most of the frazil observations stem from the periods without pancakes. The following discussion thus refers mainly to the state of frazil ice in the absence of pancakes.

It is recalled that all experiments started from similar conditions, with ice formation commencing after an initial cooling period when the water had reached its freezing point. In experiments E2 and E4 however, no observations are available during the first hours of ice growth, as we did not have access to the laboratory during night time. From the thickness observations and the heat fluxes (Fig. 7) our observations likely started $5-10 \mathrm{~h}$ after the onset of freezing. None of the CTD instruments indicated any supercooling, temperatures being mostly $0.01-0.04 \mathrm{~K}$ above the freezing point. However, this does not mean that the frazil grew without supercooling. The upper instrument, at which slightly lower temperatures were measured, was still $40 \mathrm{~cm}$ from the surface, while wave heights were typically less than $10 \mathrm{~cm}$. As the strongest downward mixing of surface cooling can be expected on a length scale of the wave height, there might have been supercooling near the surface. For example, Smedsrud (2000) showed temperature profiles, with 0.04 $0.06 \mathrm{~K}$ lower temperatures near the surface of this tank, compared to the bottom. We also see, in one of the tanks, a 0.02 $0.03 \mathrm{~K}$ higher bottom temperature than that measured by the CTD at mid-depth, but do not have profile information. The presence of such a gradient would be consistent with a slight supercooling of a few hundredths of a degree, as reported for studies with similar moderate heat fluxes (e.g. Carstens, 1966; Osterkamp et al., 1983; Clark and Doering, 2009).

\subsection{Salinity}

Frazil salinities are found to decrease, over the course of one day, from average values slightly above 30 to values close to 25. This result is very robust for all experiments. In De la Rosa et al. (2011) we already reported on this result for 
an extended period of E2, when frazil was sampled between pancakes. The initially higher salinities were not observed in E2 and E4, where no samples were obtained during the first 5-10 h. While for E1 and E3 our highest values appear large, Onstott et al. (1998) also reported an initial salinity of 29 for thin grease ice growing from a water salinity of 30 , and also observations obtained by Reimnitz et al. (1993) for very young frazil are comparable.

Our approach to present ice salinities as in situ values is different from what most authors have presented in previous work. In most studies the authors have drained and sieved the frazil, as we did, yet interpreted this residual salinity in terms of the potential entrapment of frazil ice, without computing the intrinsic salinity from the solid fraction. We think that the approach of using sieved or drained salinities alone is of limited value due to the following reasons: firstly, the drainage protocol is subjective, as factors such as time and intensity of shaking, temperature and cohesion of frazil at sampling, temperature in air and of sieve are hardly reproducible from study to study. Secondly, the salt adhering to the frazil crystals after sieving is likely a function of their specific surface area that may be different for older ice, while the bulk salinity may be less affected.

Nevertheless, we consider some previous observations of drained frazil ice: in the laboratory, Martin and Kauffman (1981) reported that $31 \%$ of the salt from a $38.4 \mathrm{~g} \mathrm{~kg}^{-1} \mathrm{NaCl}$ solution remained in the frazil. For their solution this corresponded to $11.8 \pm 2.1 \mathrm{~g} \mathrm{~kg}^{-1}$, while, after scaling for standard seawater ${ }^{1}(35)$, this corresponds to a frazil salinity of 10.9. Reimnitz et al. (1993) obtained a range of 12 to $20 \mathrm{~g} \mathrm{~kg}^{-1}$ (water salinity of $32 \mathrm{~g} \mathrm{~kg}^{-1}$ ) for young frazil accumulating at the surface of a tank, while Wilkinson (2005) report values in the range 16 to $26 \mathrm{~g} \mathrm{~kg}^{-1}$ for a similar tank experiment as ours. In the field, Smedsrud (2001) noted salinities of sieved slush in the range 20 to 28 (water salinity 36), while Smedsrud and Skogseth (2006) reported 16 to 28 (water salinity 33 to 35 ) for observations in Svalbard fjords. Doble (2007) reported drained frazil salinities in the Weddell Sea between 8 and 19, decreasing from the outer ice edge (14 to 19 ), via the middle and inner ice zone (10 to 15 ) to the long scale distance ( 8 to 12 ). Wadhams and Wilkinson (1999) reported, for frazil and slush collected between pancakes in the Greenland Sea, even a larger range of 5 to 22 .

Hence, drained oceanic grease ice salinities span a range of 5 to 28 , with a tendency to decrease with age. Our drained salinities also decrease with time (not shown in the present study) and lie within the range 14 to $26 \mathrm{~g} \mathrm{~kg}^{-1}$, similar to those obtained by Wilkinson (2005) under similar conditions. The apparent lower salt-content of older frazil is consistent with coarsening during aging. This aspect is discussed in Maus and De la Rosa (2012), where we combine sieved and

\footnotetext{
${ }^{1}$ per definition a seawater salinity of 35 corresponds to a salinity of $35 \times 1.005 \mathrm{~g} \mathrm{~kg}^{-1}$
}

bulk salinities to discuss frazil morphology. Here we like to point out that drained grease ice salinities appear to be much more variable than undrained salinities (decreasing in our study only from 30 to $25 \mathrm{~g} \mathrm{~kg}^{-1}$ ), and that proper modelling of salt fluxes requires the intrinsic, not the drained salinity, see De la Rosa et al. (2011).

\subsection{Solid volume fraction}

The solid volume fraction and ice salinity are related to each other by Eqs. (1) and (2). For young frazil, when the brine salinity is close to the seawater value, the volume fraction $v_{\mathrm{S}}$ is thus proportional to $\left(1-S_{\mathrm{i}} / S_{\mathrm{w}}\right)$ and increases with decreasing ice salinity. The time-series of average volume fractions (Fig. 5 c, d) shows an increase from low ice initial values of 0.05 to 0.3 over the course of one day.

To analyze the increase in solid fraction due to packing we have considered a simple model, where the compaction rate is proportional to the state of compaction. This resulted in Eqs. (7) and (9) for the solid fraction that may be fitted by least squares to obtain the initial solid fraction $v_{\mathrm{s} 0}$ at the onset of ice formation, a maximum solid fraction $v_{\mathrm{S}_{\max }}$, and a decay time- or length scale of the compaction process. The time-dependent fit was only determined with high temporal resolution for E1 (Fig. 10c). The fit where the compaction increases with the equivalent ice thickness was applied to the data from E1 only (Fig. 10b) and all experiment runs (Fig. 10a). The approach yielded $0.03<v_{\mathrm{s} 0}<0.05$ for the initial solid fraction, $0.23<v_{\mathrm{s}_{\max }}<0.31$ for the maximum, as well as a $95 \%$ decay time $3 t_{c}=18$ to $21 \mathrm{~h}$ from the timeexponential fit. The corresponding equivalent thickness decay scale was $3 H_{c}=0.42$ to $0.57 \mathrm{~cm}$ for E1 and $3 H_{c}=0.99$ to $1.2 \mathrm{~cm}$ when all experiments are fitted. With a constant heat flux, the equivalent thickness production should be proportional to $Q /\left(L_{\mathrm{f}} \rho_{s}\right)$, and we may convert $3 H_{c}$ to a decay time scale of 5.1 to $6.9 \mathrm{~h}$ for E1 and 12.0 to $14.5 \mathrm{~h}$ for all data. This result is considerably smaller than from the time-fit. The difference can be attributed to the fact that the time-fit considers the average solid fraction, while the thickness-based compaction limit is related to the surface maximum. Also, while the fit against time yields an average response from all tank locations, it does not account for advection and redistribution; i.e., as long as ice accumulates strongly at the end of the tank, the remaining tank contains younger ice, weakening a possible frazil-time relationship. It is thus the fit against the equivalent thickness that sorts the ice samples most reliably, being less biased by advection. The fit based on all data then indicates that most of the packing (95\%) is achieved after 1 to $1.2 \mathrm{~cm}$ of equivalent ice growth. The lower E1 estimate $(0.42$ to $0.57 \mathrm{~cm})$ for the decay thickness scale, may have to do with the shutdown of the wave-paddles from hours 911 in this experiment. In general, the thickness-based compaction is physically consistent with the mechanism of packing by loading (equivalent ice mass and buoyancy). 
To interpret these values we need to note that the change in solid fraction, as we have monitored it, does not only resemble the packing of existing ice. It results from three processes: (i) packing of existing frazil, (ii) growth and coarsening of existing crystals and (iii) secondary nucleation of new crystals. Points (ii) and (iii) are related to ice growth due to the ongoing heat loss. However, these two thermodynamic processes will counteract each other. On the one hand, (ii) may be thought to take place within the existing surface grease ice, thus increasing the solid fraction by growth of crystals. On the other hand, (iii) will decrease the solid fraction, at least over the depth of the order of the wave height, if nucleation of crystals takes place within the water column, followed by their settling as high porosity frazil at the bottom of the grease ice layer. We obtained a simple solution to this problem by integrating Eq. (7) to obtain the average solid fraction, assuming that the local solid fraction is a function of the accumulated frazil mass below it. For a validation and first-order empirical distinction between packing, aging, and new bottom agglomeration, vertical profiles in the solid fractions and observations of crystal size spectra would be needed, which we do not have. Approaches to crystal growth and nucleation on the basis of existing models (e.g. Tsang and Hanley, 1985; Svensson and Omstedt, 1994; Wang and Doering, 2005) would in addition require the vertical distribution of supercooling, in particular near the surface. Without these observations, we cannot distinguish the contributions, neither through empirical means, nor by model validation. Hence, it is important to note that we currently do not know to what degree the determined decay scales depend on the experimental conditions like wave-induced mixing, wave amplitude, ice thickness and heat flux. However, there are some general results that can be pointed out:

First, Fig. 4a shows that during E1 (both tanks) there is a persistent increase in the bulk frazil thickness $H_{\mathrm{i}}$ over at least $20 \mathrm{~h}$, after which it eventually becomes uniform. This can also be seen in E2 and E4 if the observations are moved forward in time by an offset of 5-10 h, due to the presence of frazil crystals when the experiment started. Therefore, secondary nucleation and growth in the water column, implying thickness increase rather than internal freezing of existing frazil, is always present. An interesting event is noted (not shown): during E1 near hour 9, the thickness rather abruptly increased by $\sim 1 \mathrm{~cm}$, while the temperature recorded by the CTD instruments also increased. This signal, measured in both tanks, is apparently related to the wave-paddle stop and may reflect the sudden upward settling of frazil submerged in the water column. From the $\sim 1 \mathrm{~cm}$ thickness increase and a typical solid fraction of 0.1 for the early packing mode (I) in Fig. 6, as well as the depth of the tank below the ice $(85 \mathrm{~cm})$, we can obtain an estimate $(1 / 85) \times 0.1 \approx 0.0012$ for the suspended frazil volume fraction. Although data are in general sparse, values of a few tenths of a percent have been proposed on the basis of observations in flumes and rivers (Tsang, 1986; Marko and Jasek, 2010). In a similar tank experiment, albeit under the presence of currents rather than waves, Smedsrud $(2000,2001)$ observed average solid fractions around 0.001 . However, in the latter experiments, sediments may have influenced the suspension capability.

Secondly, both the time and thickness fits yield a similar $v_{\mathrm{s} 0}$ in the range 0.03 to 0.05 at the onset of frazil formation. This corresponds to the first frazil observed at the surface. It is tempting to interpret this result in terms of a critical frazil concentration at which crystal interaction becomes too strong to keep the particles in suspension. The related balance between crystal rise velocity and turbulence production has been pointed out by modellers; e.g., Omstedt and Svensson (1984); Svensson and Omstedt (1994); Wang and Doering (2005). Also, when flocculation becomes large due to crystal interaction, larger crystal ensembles may form and float to the surface. Although this is a very important general aspect, i.e. for proper model simulation and validation (e.g. Omstedt and Svensson, 1984), so far there exist few observations. Considering that maximum suspended volume fractions are an indication of a critical value, we note that Osterkamp et al. (1983) estimated, based on conductivity measurements, short-term maximum suspended ice volume fractions of $0.008-0.047$ in a subarctic stream, while Tsang (1986) estimated 0.01-0.02. However, we need to note that our comparable $0.03-0.05$ range may also be related to our sampling technique: our first low-porosity ice samples were typically $0.5-1 \mathrm{~cm}$ in thickness and it is plausible that a frazil volume fraction of 0.001 existed mixed within the water column; sampling $30 \mathrm{~cm}$ of the water column with the cylinder we used would then create a volume fraction of 0.03-0.06 if the sampled frazil rose towards the surface and accumulated as a $0.5-1 \mathrm{~cm}$ grease layer. A sampling time of $1 \mathrm{~min}$ would be sufficiently long to allow for this process. Hence, the range 0.03-0.05 may not reflect a critical concentration for suspension, but rather the early accumulation of very loose frazil that just has risen to the surface. In order to study how and if the transition depends on the turbulence level, rate of ice formation and crystal shapes, more observations under different growth conditions are needed.

The maximum solid fraction was obtained here by maximizing the correlation of the exponential fit to the data. Also, the packing law we present is tentative, and assumed as an equation of the type that often describes natural growth and decay processes. Yet, the observations are fitted reasonably well with this approach. The maximum solid fraction as well as the decay time, reflect a combination of packing and crystal growth, and their interaction. The processes are not expected to be additive: e.g., when internal freezing increases the solid fraction, this may be expected to decrease the mechanical packing rate, whereas settling of new loose crystals will enhance it. As mentioned, we do not intend to speculate on these interactions, on the basis of the present data. However, we can interpret the histogram distribution in Fig. 6 in the following manner: two prominent peaks in the solid fraction are seen, one in the range $0.08-0.12$ (labelled as mode 
I), the other in the range $0.18-0.26$ (labelled as mode II). As the lower peak is only seen in E1 and E3, it appears to be related to the early growth phase. Note that these are the average solid fractions from Eq. (9), while the surface values from Eq. (7) are higher. An early $\overline{v_{\mathrm{s}}}=0.1$ corresponds to a surface $v_{\mathrm{s}}$ of 0.15 , while the second mode gives surface values from 0.25 to 0.28 . As the average values are influenced by accumulation of loose frazil from below, one may also interpret the surface values as the mechanical packing limit. Mode II is very broad. Such behaviour appears to be consistent with a first phase dominated by mechanical packing, followed by a second phase where internal crystal growth increases the solid fraction further, as for a constant heat flux the distribution becomes rather constant. This interpretation is also consistent with the observation that above a solid fraction of approximately 0.3 the surface begins to become solid. While up to this limit internal freezing also takes place, the grease still remains a mushy layer and does not freeze-up. If it does, such ice would no longer be classified as grease ice, and consequently only a few (14) high solid fraction samples exist in our data. Our earlier analysis of the frazil-pancake transition, during the second day of E2 from hour 19 to 43 (De la Rosa et al., 2011), also supports this observation: the grease ice solid volume fraction, sampled between the pancakes, remained rather constant around $0.27 \pm 0.02$. In Maus and De la Rosa (2012) we summarise additional published and unpublished data sources that support the present results. Noting that solid fractions were often overestimated, when computed for drained ice samples, we concluded that very young frazil appears to have solid fractions in the range $0.05<v_{\mathrm{s}}<0.15$, while 0.3 seems to be an appropriate upper limit for grease ice.

\subsection{Frazil-pancake transition}

We can draw on these results by considering the onset of pancake formation, which took place after 17-21 h in E1 and E2 compared to 3-5 h in E3 and E4. In E3 predominantly small pancake-like shuga formed, and E4 thus appears to be the only experiment with early formation of large $(\sim 20 \mathrm{~cm})$ pancakes. However, E4 is different in terms of its much lower wave amplitude $(\sim 1 \mathrm{~cm}$ compared to $3-6 \mathrm{~cm}$ in other experiments). We thus focus here first on experiments E1 and E2.

The onset of shuga and pancake formation in E1 was observed after approximately $17 \mathrm{~h}$. Comparison with Fig. 10c shows that this is comparable to 3 times the decay time scale $3 t_{c} \approx 18 \mathrm{~h}$ for the solid fraction. That the decay time scale estimated from the heat flux and the thickness decay scale in E1 was only $5-7 \mathrm{~h}$ is, as mentioned, related to the fact that the time-fit considers average solid fractions, while the thickness-fit derives a transition from a, presumably higher, surface solid volume fraction. The comparison suggests that it is the average solid fraction that is related to pancake formation, which is plausible because the grease ice continues to be mixed by the waves. In other words, the onset of pancake formation corresponds to the state when $1-e^{-3} \approx 95 \%$ of the maximum compaction of the frazil has taken place. This result is consistent with the described compaction-freeze-up. Once frazil ice has reached its maximum mechanically packed state, any further increase in solid fraction due to freezing will imply the freezing of crystals to each other and thus the onset of pancake formation. The fitted critical range $0.23<v_{\mathrm{S}_{\max }}<0.31$ for the transition should also be viewed in connection with a statistical distribution of solid fractions: i.e., when it is reached, there are already some locations with higher solid fractions where pancake formation starts. In Fig. 10c there is, after $17 \mathrm{~h}$, an increasing number of solid fractions in the range above 0.3 , with a maximum of 0.43. Hence, as already pointed out from Fig. 6 and from the timing of pancake observations and compaction, a solid fraction range $0.3-0.4$ appears as the regime where pancakes ultimately start to form locally. Turning back to E4, this view is finally consistent with the early onset of pancake formation in this experiment, where average solid fractions above 0.2 were already present after a few hours (see Fig. $5 \mathrm{c}$ and d).

That pancakes generally are thinner than the frazil ice surrounding them (we found a factor of roughly $2 / 3$, as mentioned in Sect. 4.4) is consistent with the fact that heat is removed at the surface, and freezing of crystals to each other will be initiated there. Concerning the freezing from the top, in our earlier study of the second phase of E2 (De la Rosa et al., 2011) we used additional infrared surface temperature observations to distinguish between pancake and frazil/grease ice. From this classification we found a transition to pancakes when surface temperatures are $0.7-0.9 \mathrm{~K}$ below the freezing point of seawater underneath and estimated $0.37-0.40$ for the solid fraction transition to pancakes. This observation is supported from the present analysis of all experiments. While other authors have not explicitly analysed the transition, it is consistent that the highest frazil and grease ice solid fractions observed in other studies (see above) do not exceed 0.3-0.4.

\subsection{Influence of waves}

It may be postulated that the grease ice layer thickness stops increasing, once it reaches a certain thickness that depends on wave height. The general role of waves in the problem is apparent: they are the source of the turbulence that keeps the frazil ice in suspension. Once there is too much ice in the water and the crystals form large assemblages, the waves are no longer capable to do so. This appeared to happen quite rapidly, with a grease ice skim covering the surface after a few hours. However it then took much longer time for the grease ice layer to freeze into solid pancakes. The waves, thus, play a role in keeping the grease ice in internal motion and thereby prevent freezing.

As already mentioned, during E1, with wave amplitudes of $2.8-3.3 \mathrm{~cm}$, pancake formation began after $17-21 \mathrm{~h}$, while 
during E4, with amplitude of $1.0-1.2 \mathrm{~cm}$, it began after $5 \mathrm{~h}$. However, the transition time in $\mathrm{E} 4$ with respect to the start of ice production should be increased by 5 to $10 \mathrm{~h}$ (see Fig. 7), giving a corresponding pancake formation onset after 10-15 h. Also for E2 such a correction would yield an increase in the pancake formation onset time to 29-31 h, and in the latter experiment the wave amplitude was indeed largest, initially $4.6-6.0 \mathrm{~cm}$. However, in E2 the wave amplitude was then decreased to $2.5 \mathrm{~cm}$, after which pancake formation set in immediately. Hence, although the evaluation remains qualitative, there is support that the time when pancake formation starts increases with increasing wave amplitude.

Taking the simplest view, that frazil is mixed on the order of the wave height, however does not consider the feedback that frazil also influences the wave field and amplitude. This was considered in Fig. 9, where both the average wave height and its decay coefficient in the centre of the tank are plotted against the ice thickness normalised by the wave height: $h=H_{\mathrm{i}} / \mathrm{w}_{h}$. Results are most consistent for the attenuation rate, when the latter is normalised by the different background noise levels in tanks A and B (Fig. 9c). During the first period, wave height is rather constant and wave decay, related to reflections in the tank, is not affected by the increasing ice thickness. When the thickness reaches 0.5-0.6 of the wave height, i.e. a value close to its amplitude, damping increases linearly with thickness. Finally, when the ice thickness reaches 0.7 to 1 times the wave height, the damping becomes very strong and wave height decays considerably. This regime was reached during E1 when the ice thickness reached $4.5-6 \mathrm{~cm}$, after approximately $15 \mathrm{~h}$., coinciding with the formation of the first pancakes. Wave damping, once it sets in, may thus have a two-fold effect. First, it no longer stirs the frazil crystals in the grease ice layer, leading to compaction. Second, it implies that the heat released to the atmosphere (from the roof cooling aggregate) derives from a thinner water layer and grease ice. Both processes are favourable for an increased solid fraction and the onset of pancake formation.

Another aspect to be discussed in this context is the normalised ice thickness to which the frazil may grow after the onset of strong wave damping. During E4 wave heights were small and the grease ice thickness reached 3 times the wave height by the end of the experiment. On the other hand, during E1 and E3, the thickness of 1.5 times the wave height was still increasing at the end of the experiments. For comparison, we obtained from Table 1 in Martin and Kauffman (1981), an average ratio of $H_{\mathrm{i}} / \mathrm{w}_{h}=2.3 \pm 0.7$ for the location within the grease ice where the amplitude had decayed to typically $1 / 4$ of its initial value (noted as "dead zone" by the authors). It thus appears that frazil may accumulate to 2-3 times the wave height, even when the waves are strongly damped, and that most of our experiments were too short to reach this limit. Also in tank experiments reported by Leonard et al. (1998) $H_{\mathrm{i}} / \mathrm{w}_{h}$ appears to reach values slightly above 1 (their Figs. 3 to 7), but their observations span less than $20 \mathrm{~h}$. More observations under varying heat flux and wave conditions are needed to better constrain such a bound.

\subsection{Heat fluxes}

Heat flux in each tank was evaluated from Eq. (1) based on observed cooling rates, prior to freezing, and from the change in ice bulk mass during the runs. The latter method yields less accuracy, due to an inhomogeneous wave field, advection along the tank, and observational uncertainties of solid fraction. Unfortunately, no observations of solid ice growth were obtained in the quiet tank for calibration. However, for E1 the spatial and temporal resolution was sufficient to derive the net heat flux with $10 \%$ accuracy. In general the results suggest that the heat loss from the surface is not kept constant by the cooling aggregate. The observations with high significance are consistent with a heat flux that is proportional to the temperature difference between the ice/water surface and a fixed level above, $Q=k_{\mathrm{a}}\left(T_{\mathrm{a}}-T_{\mathrm{s}}\right)-Q_{0}$. Here we reconcile the equation with the term $Q_{0}$, the heat flux that presumably takes place through the tank wall and bottom. An interesting event in this context was the wave paddle stop that took place from hour 9-11 in E1. This corresponded to an increase of $0.02-0.03 \mathrm{~K}$ in the temperatures recorded at all four CTD instruments (Fig. $2 \mathrm{~b}$ and c), at 40 and $65 \mathrm{~cm}$ depth of the $85 \mathrm{~cm}$ deep tank. This warming rate, if it occurred over the whole tank, corresponds to a heat flux of $10-15 \mathrm{Wm}^{-2}$. We interpret this value as the heat that the tank receives through its bottom and sidewalls (there was some warming from the facility below the laboratory). This suggests that the heat fluxes given in Fig. 8 are net heat fluxes, whereas the surface forcing is likely larger by this amount. Note also that the temperature, after restarting the wave paddle, returns to its original value after just half an hour, corresponding to a net heat loss of $60 \mathrm{Wm}^{-2}$, which is the value derived for this experiment. Hence, wave motion appears, at least in E1, effective enough to distribute the heat loss over the whole water column. The role of surface and turbulent heat fluxes for wave - grease interaction may be illustrated by considering ice growth with $d\left(H_{\mathrm{i}} v_{\mathrm{s}}\right) / d t=Q /\left(L_{\mathrm{f}} \rho_{s}\right)$ and assuming that $H_{\mathrm{i}}$ becomes constant or changes little due to a wave imposed limit. In this situation the rate in solid fraction increase $d v_{\mathrm{s}} / d t$ will become proportional to the heat flux, if the heat is removed from the grease ice layer alone. However, due to wave-induced mixing, only a fraction of heat is released by freezing near the surface - the remaining heat comes from nucleation of crystals within the water column, and from the heat input through the tank walls. We emphasize again that, to evaluate mechanical compaction and internal freezing of grease ice, observations of temperature and crystal size distribution in the water column, as well as in the grease ice itself would be necessary. 


\subsection{Grease ice temperature and brine salinity}

The findings discussed above show that profiles of solid fraction would improve our understanding of the packing and consolidation process of grease ice. The same is true for the salinity and temperature of the liquid fraction of grease ice, the brine. In the present work we have assumed that due to wave-stirring, this brine has the properties of the seawater on which the grease floats, with the temperature given by the freezing point of seawater. This assumption is due to a lack of observations as we, unfortunately, did not measure the salinity of the brine. From IR surface temperature observations of the second phase of E2, when pancake formation had started, De la Rosa et al. (2011) found a characteristic surface temperature of frazil that was $0.47 \mathrm{~K}$ lower than the seawater below. However, this signal is likely restricted to the very surface skim (see Katsaros, 1973). The thermistor data from the present study (not shown) indicated that the frazil temperature was not more than $0.1 \mathrm{~K}$ below the temperature of the water, but the accuracy was too low to derive any significant difference. Other studies (Maus and De la Rosa, 2012) suggest that grease ice seldom deviates by more than $0.1 \mathrm{~K}$ from the water underneath, and may have brine salinities $1-2 \mathrm{~g} \mathrm{~kg}^{-1}$ above the water values. As discussed in Sect. 3.4, this correction would result in 0.01-0.02 higher solid fractions and modes derived in our study. Hence, while obtaining profiles of brine salinities and temperatures in grease ice is no easy task, at least drained brine should be systematically collected.

\section{Summary and conclusions}

In the present study we have analyzed the growth of frazil ice under the presence of waves. Our main focus was to describe the evolution of its salinity and solid fraction during its accumulation in a floating grease ice layer, until its transition into solid pancakes. Derived solid fractions and salinity refer to frazil ice in situ, rather than sieved frazil crystals, and we recommend to use this approach to describe frazil properties.

Frazil ice growth and accumulation in our experiments proceeded, in accordance to earlier studies, as follows: A water column, mixed by wave-generated turbulence, was cooled to - and likely supercooled some hundredths of a degree below - the freezing point. Growth of frazil crystals then started and released latent heat. Ice growth then proceeded, without major changes in the temperature, driven by the heat loss from the tank. After a few hours, a surface grease ice skim of low porosity and a few millimetres in thickness was observed. It increased subsequently growing in thickness and solid fraction until, 10-30 h after the start of ice formation, when the first pancakes appeared. Based on our observations we identified these regimes with the following transitions in terms of the solid fraction and thickness:
1. The first grease ice that appears at the surface (interpolating the results to zero thickness), has a solid fraction of $0.03-0.05$. Although we think that this value likely relates to sampling of the water column, for which frazil with a volume fraction of typically 0.001 was estimated, it indicates the lowest packing that frazil may obtain at the surface. It further points to the important question: at which volume fraction do particles in a frazil suspension begin to interact rigorously to from clusters that float to the surface?

2. A histogram of all solid fractions obtained shows a broad solid fraction peak in the range 0.18-0.26, with almost no frazil having solid fractions above the latter value, yielding a tentative upper limit for the solid fraction of frazil.

3. The solid fraction evolution prior to the onset of pancake formation can be approximated by an exponential compaction law, from which a maximum solid fraction of 0.23-0.31 was estimated. In terms of a decay time scale, it took 18-21 h until $95 \%$ of the frazil compaction to its maximum solid ice fraction was reached. In terms of a thickness scale, the transition at the very surface was related to the accumulation of 1.0 to $1.2 \mathrm{~cm}$ equivalent ice thickness.

4. The decay time scale approximately coincided with the onset of pancake formation.

5. Strong wave damping is first observed when the ice thickness reaches $0.7-0.9$ times the wave height. This transition corresponds to the $95 \%$ decay time of the solid fraction and the onset of pancake transition as well.

If we consider the thickness-dependent analysis of all experiments E1-E4 as the best estimate, this gives 0.04 to 0.05 for the minimum in (1) and $0.28-0.31$ for the maximum in (2). These solid fraction ranges would be larger by 0.02 , if brine salinities exceed seawater by $2 \mathrm{~g} \mathrm{~kg}^{-1}$, which is a plausible upper bound (Maus and De la Rosa, 2012). From these findings we conjecture that there is a critical solid fraction of dense frazil ice suspensions, above which any further increase will lead to the formation of a solid ice matrix, i.e., pancake ice. According to (3) and (4) this transition appears to depend on wave action. Once waves are strongly damped, the grease ice is no longer stirred, latent heat is released preferentially from crystals close to the surface and freezing into solid pancakes begins. While the details of how grease ice porosity, heat transport and waves interact to delay and initiate freeze-up still remain challenging, the present dataset and analysis provides some parameter estimates and hypothesis to guide future modelling of grease and frazil ice.

First, basic models of nucleation and surface skim formation (e.g., Omstedt and Svensson, 1984) may be further 
developed and validated including a time-dependent solid fraction, as well as the critical concentration at which frazil crystals tend to accumulate at the surface.

Second, the opening and closing time scale of leads and polynyas is strongly related to the ratio $\left(L_{\mathrm{f}} \rho_{\mathrm{i}} H_{\mathrm{i}} v_{\mathrm{s}}\right) / Q$, wherein both ice thickness $H_{\mathrm{i}}$ and solid fraction $v_{\mathrm{s}}$ appear (e.g., Bauer and Martin, 1983; Pease, 1987; Biggs et al., 2004). So far the solid fraction has been treated as constant in most models. The present study suggests decay time scales for the solid fraction of more than half a day, indicating that its treatment in many model applications may be important. The results of this study can also be relevant to device the transition from a grease to pancake ice cover on the basis of thermodynamic constraints for the solid ice volume fraction. Such approaches may improve presently incomplete theories of grease ice viscosity and wave damping (e.g., Jenkins and Jacobs, 1997; De Carolis, 2005; Wang and Shen, 2010a, 2010b).

Finally, we would like to note that the importance of freezing processes in turbulent seawater may increase in the future, given the transformation of the Arctic sea ice cover. Decreases in the sea ice extent in summer have been - and are predicted to be - relatively large compared to the winter (e.g., Serreze et al., 2007). Frazil ice growth may thus become more common in the near future, expanding the seasonal ice zone area with implications for upper layer oceanography and thermodynamics.

Acknowledgements. This work describes the RECARO project (Principal Investigator: Jeremy Wilkinson from the Scottish Association for Marine Science) supported by the European Community's Sixth Framework Programme through the grant to the budget of the Integrated Infrastructure Initiative HYDRALAB III, Contract no. 022441(RII3). The work was completed as part of the NorClim project, funded by the Norwegian Research council. We thank the Hamburg Ship Model Basin (HSVA, www.hsva.de), especially the ice tank crew, for the hospitality, technical and scientific support and the professional execution of the test program in the Research Infrastructure ARCTECLAB. Ruixue Wang (Uni. Manitoba, Canada) is thanked for providing the wave data and for valuable discussions, Lars H. Smedsrud (Univ. Bergen, Norway) for his help with measurements, Hayley Shen (Potsdam, USA) and Shigeki Sakai (Univ. Iwate, Japan) are thanked for providing pancake observations and Marcel Nicolaus (AWI, Germany) for the thermometer sensor data. Peter Haugan, Martin Miles (Univ. Bergen, Norway), Laurent Bertino (NERSC, Norway) and three anonymous reviewers are acknowledged for their reviews of text and constructive suggestions for improvement. The first author finally thanks Trond Mohn c/o Frank Mohn AS for providing partial funds for this work.

Edited by: H. Eicken

\section{References}

Bauer, J. and Martin, S.: A Model of Grease Ice Growth in Small Leads, J. Geophys. Res., 88, 2917-2925, 1983.

Biggs, N. R. T., Austin, L. M. C., and Willmott, A. J.: A model for the closure of a two-dimensional coastal latent heat polynya, Oc. Model., 7, 211-226, 2004.

Carstens, T. J.: Experiments with supercooling and ice formation in flowing water, Geofys. Publ. Norway, 26, 3-18, 1966.

Clark, S. P. and Doering, J. C.: Frazil flocculation and secondary nucleation in a counter- rotating flume, Cold Reg. Sci. Technol., 55, 221-229, 2009.

De la Rosa, S., Maus, S., and Kern, S.: Thermodynamic investigation of an evolving grease to pancake ice cover, Ann. of Glaciol., 52, $206-214,2011$.

De Carolis, G., Olla, P., and Pignagnoli, L.: Effective viscosity of grease ice in linearized gravity waves, Fluid Mech., 535, 369381, 2005.

Doble, M.: Growth and motion at the Weddell Sea-ice edge, University of Southampton, Faculty of Engineering Sciences and Mathematics, School of Ocean and Earth Sciences, Doctoral Thesis, 170 pp., 2007.

Fofonoff, N. P. and Millard Jr., R. C.: Algorithms for computation of fundamental properties of seawater, UNESCO Tech. Pap. Mar. Sci., 44, 53 pp., 1983.

Jenkins, A. D. and Jacobs, S.: Wave damping by a thin layer of viscous fluid, Phys. Fluids, 9, 1256-1264, 1997.

Katsaros, K. B.: Supercooling at the surface of an Arctic lead, J. Phys. Oceanogr., 3, 482-485, 1973.

Kaufmann, D.: Sodium chloride: the production and properties of salt and brine, Washington, DC, American Chemical Society, 1960.

Kinnard, C., Zdanowicz, C. M., Koerner, R. M. and Fisher, D. A.: A changing Arctic seasonal ice zone: Observations from 18702003 and possible oceanographic consequences, Geophys. Res. Lett., 35, L02507, doi:10.1029/2007GL032507, 2008.

Leonard, G. H., Shen, H. H., and Ackley, S. F.: Dynamic growth of a pancake ice cover, in: Ice in surface waters: Proceedings of the 14th International IAHR Ice Symposium, edited by: Shen, H. T., Taylor \& Francis, Rotterdam, ISBN: 90/5410/9718, 1998.

Marko, J. R. and Jasek, M.: Frazil monitoring by multi-frequency Shallow Water Ice Profiling Sonar (SWIPS): present status, Proceedings of 20th International Symposium on Ice, Lahti, Finland, 12 pp., 2010.

Martin, S. and Kauffman, P.: A field and laboratory study of wave damping by grease ice, J. Glaciol., 27, 283-313, 1981.

Maus, S.: On Brine Entrapment in Sea Ice: Morphological stability, microstructure and convection, Logos Verlag Berlin $\mathrm{GmbH}$, ISBN: 978-3-8325-1523-2, 538 pp., 2007.

Maus, S. and De la Rosa, S.: Salinity and volume fraction of grease and frazil ice, in press, J. Glaciol., 2012.

Newyear, K. and Martin, S.: A comparison of theory and laboratory measurements of wave propagation and attenuation in grease ice, J. Geophys. Res., 102, 25091-25099, 1997.

Omstedt, A. and Svensson, U.: Modelling supercooling and ice formation in a turbulent Ekman layer, J. Geophys. Res., 89, 735744, 1984.

Osterkamp, T. E., Gilfilian, R. E., Gosink, J. P., and Bensen, C. S.: Water temperature measurements in turbulent streams during periods of frazil-ice formation, Annals of Glaciology, International 
Glaciological Society, Proceedings of the Second Symposium on Applied Glaciology, 4, 209-215, 1983.

Pease, C.: The size of wind-driven coastal polynyas, J. Geophys. Res., 92, 7049-7059, 1987.

Reimnitz, E., Clayton, J. R., Kempema, E. W., Payne, J. R. and Weber, W. S.: Interaction of rising frazil with suspended particles: tank experiments with applications to nature, Cold Reg. Sci. Technol., 21, 117-135, 1993.

Serreze, M. C., Holland, M. M., and Stroeve, J.: Perspectives on the Arctic's shrinking sea-ice cover, Science, 315, 1533-1536, 2007.

Smedsrud, L. H.: Incorporation of sediments into sea ice in coastal polynyas in the Kara sea, Report, Norwegian Polar Institute, Troms $\varnothing$, Norway, 2000.

Smedsrud, L. H.: Frazil ice entrainment of sediment: large tank laboratory experiments, J. Glaciol., 47, 461-471, 2001.

Smedsrud, L. H. and Skogseth, R.: Field measurements of Arctic grease ice properties and processes, Cold Reg. Sci. Technol., 44, 171-183, doi:10.1016/j.coldregions.2005.11.002, 2006.

Svensson, U. and Omstedt, A.: Simulation of super cooling and size distribution in frazil ice dynamics, Cold Reg. Sci. Technol., 22, 221-233, 1994.

Tsang, G.: Preliminary report on field study at Lachine Rapids on cooling of river and river and formation of frazil and anchor ice. Proceedings of the 4th Workshop on Hydraulics of River Ice, Montreal, F5.1-5.51, 1986.

Tsang, G., and Hanley, O'D. T.: Frazil formation in water of different salinities and supercoolings, J. Glaciol., 31, 74-85, 1985.
Wadhams, P. and Wilkinson, J. P.: The physical properties of sea ice in the Odden ice tongue, Deep-Sea Research II, 46, 1275-1300, 1999.

Wadhams, P., Squire, V. A., Goodman, D. J., Cowan, A. M., and Moore, S. C.: The attenuation rates of ocean waves in the marginal ice zone, J. Geophys. Res., 93, 6799-6818, 1988.

Wang, S. M. and Doering, J. C.: Numerical simulation of supercooling process and frazil ice evolution, ASCE J. Hydraul. Eng., 131, 889-897, 2005.

Wang, R. and Shen, H.H.: Experimental study of surface wave propagating through a grease-pancake ice mixture, Cold Reg. Sci. Technol., 61, 90-96, 2010a.

Wang, R. and Shen, H. H.: Gravity waves propagating into an ice?covered ocean: A viscoelastic model, J. Geophys. Res., 115, C06024, doi:10.1029/2009JC005591, 2010b.

Wang, R., Shen, H. H., and Evers, K.-U.: An experimental study of wave induced ice production, 19th IAHR International Symposium on ice, Vancouver, British Columbia, Canada, 2008.

Wilkinson, J.: Sea ice, convection and the Greenland Sea, University of Southampton, Faculty of Engineering Science and Mathematics, School of Ocean and Earth Science, Doctoral Thesis, 234 pp., 2005.

Wilkinson, J. P, DeCarolis, G., Ehlert, I., Evers, K.-U., Gerland, S., Hughes, N., Jochmann, P., Kern, S., Nicolaus, M., Notz, D., De la Rosa, S., Sakai, S., Shen, H., Smedsrud, L. H., and Wadhams, P.: Ice tank experiments highlight changes in sea ice types, EOS Trans. AGU 10, 81-82, doi:10.1029/2009EO100002, 2009. 